

\title{
Laser surface melting of nickel-based alloy reduces nickel release in the primary cooling system of a nuclear power plant
}

Wilfried Pacquentin, Lucille Gouton, Nadège Caron, Charles Brussieux, Marc Foucault, Patrice Peyre, Hicham Maskrot, Véronique Favier

\section{To cite this version:}

Wilfried Pacquentin, Lucille Gouton, Nadège Caron, Charles Brussieux, Marc Foucault, et al.. Laser surface melting of nickel-based alloy reduces nickel release in the primary cooling system of a nuclear power plant. Optics and Laser Technology, 2021, 144, pp.107401. 10.1016/j.optlastec.2021.107401 . hal-03331246

\section{HAL Id: hal-03331246 \\ https://hal.science/hal-03331246}

Submitted on 1 Sep 2021

HAL is a multi-disciplinary open access archive for the deposit and dissemination of scientific research documents, whether they are published or not. The documents may come from teaching and research institutions in France or abroad, or from public or private research centers.
L'archive ouverte pluridisciplinaire HAL, est destinée au dépôt et à la diffusion de documents scientifiques de niveau recherche, publiés ou non, émanant des établissements d'enseignement et de recherche français ou étrangers, des laboratoires publics ou privés. 


\title{
Laser surface melting of nickel-based alloy reduces nickel release in the primary cooling system of a nuclear power plant
}

\author{
Wilfried Pacquentin ${ }^{\mathrm{a}, *}$, Lucille Gouton ${ }^{\mathrm{a}}$, Nadège Caron ${ }^{\mathrm{b}}$, Charles Brussieux ${ }^{\mathrm{c}}$, Marc Foucault ${ }^{\mathrm{c}}$, \\ Patrice Peyre $^{\mathrm{d}}$, Hicham Maskrot ${ }^{\mathrm{a}}$, Véronique Favier ${ }^{\mathrm{d}}$ \\ ${ }^{a}$ Université Paris-Saclay, CEA, Service d'Etudes Analytiques et de Réactivité des Surfaces, 91191 Gif sur Yvette, France \\ ${ }^{\mathrm{b}}$ Université Paris-Saclay, CEA, Service d'EtudeduComportement des Radionucléides, 91191 Gif sur Yvette, France \\ ${ }^{\mathrm{c}}$ Orano Equeurdreville-Hainneville, Basse-Normandie, France \\ d PIMM, UMR 8006 CNRS - Arts et Métiers ParisTech - CNAM, 75013 Paris, France
}

\section{A R T I C L E I N F O}

\section{Keywords:}

Ni-based alloy

Laser Surface Melting

Chromium oxide

Oxidation

Primary medium

Primary cooling system

Cation release

Corrosion

Nuclear reactor

Surface analysis

\begin{abstract}
A B S T R A C T
The surface of Ni-based alloy 690 was treated using a sub-microsecond pulsed laser in order to reduce the amount of nickel released when the surface is exposed to the primary cooling system of pressurized water nuclear reactors. A 2D array of laser treatment parameter sets was investigated. The results on sample surfaces was characterized using interferometric microscopy, Scanning Electron Microscopy (SEM), Glow Discharge Optical Emission Spectrometry (GDOES) and X-ray Photoelectron Spectrometry (XPS). The treatment leading to a continuous and defect-free chromine surface having the minimum nickel content over about the first two nanometers and no subsurface chromium depletion was selected for the nickel release test. This selection criterion proved to be very efficient as the total amount of nickel released in a standard qualification test using a simulated primary coolant was reduced, compared to a non-treated surface, by a factor of 7 during the heating phase and by a factor of 3.7 on average over the whole month-long test.
\end{abstract}

\section{Introduction}

Alloy 690 is an austenitic nickel based alloy used as material for steam generator tubes in nuclear power plants because of its good formability, good mechanical properties at high temperature and high resistance to stress corrosion cracking [1]. One of the main issues to overcome in pressurized water reactors (PWR) is the induced radioactive dose where deposited activities are mainly caused by ${ }^{58} \mathrm{Co}$ and ${ }^{60} \mathrm{Co}$ which are respectively the neutron activated compounds of ${ }^{58} \mathrm{Ni}$ and ${ }^{59} \mathrm{Co}$. Indeed in a primary coolant environment alloy 690 releases nickel ions [2-7]. This phenomenon occurs in parallel with a more prominent generalized corrosion process responsible for the formation of a protective oxide layer $[1,3,5,8-10]$. Nickel release in itself does not significantly affect material performance as the thickness of material involved in this release is very small and the tolerable limit on nickel release due to its consequences on radioactivity is reached well before that for material performance [9]. A correlation between the structural properties of the surface and the Ni release rate has been identified [11]. The influence of hydrogen present in the primary medium on the corrosion behaviour has been investigated [12]. Many mechanical and chemical surface treatments have been tested in order to reduce $\mathrm{Ni}$ release in operating conditions $[8,9,13-15]$ and they have led to a set of qualitative criteria expressed as surface characteristics $[8,11,14]$. The oxide layer growth in the primary coolant has been modelled as well as the cation release mechanisms $[6,16,17]$. Oxidation of $\mathrm{Ni}$ alloys in primary water chemistry generally leads to a duplex oxide [5] in which the outer layer is made of $(\mathrm{Ni}, \mathrm{Fe})$ spinels and $(\mathrm{Ni}, \mathrm{Cr})$ spinels and of a thin inner layer containing chromium-rich oxides while the exact microstructure may vary depending on conditions $[3,9,12,18]$. This surface state promotes dissolution of the alloy components in the coolant $[19,20]$. The defect density of the passive film has been shown to play an important role on the corrosion behaviour at high temperatures [17,21]. At $285{ }^{\circ} \mathrm{C}$ the diffusion coefficient of $\mathrm{Ni}$ in a chromine layer $\mathrm{V}_{\mathrm{Ni}}^{\mathrm{Cr}_{2} \mathrm{O}_{3}} \approx$ $2.510^{-25} \mathrm{~cm}^{2} / \mathrm{s}$ [15] is much smaller than in a spinel layer $V_{\mathrm{Ni}}^{\mathrm{Nir}_{2} \mathrm{O}_{4}} \approx$ $310^{-18} \mathrm{~cm}^{2} / s$ [22]. This suggests that a continuous $\mathrm{Cr}_{2} \mathrm{O}_{3}$ layer could be an efficient means for mitigation of nickel release and motivates the development of a surface treatment aiming at substituting $\mathrm{Cr}_{2} \mathrm{O}_{3}$ for the ordinary Ni-based spinels.

\footnotetext{
* Corresponding author.

E-mail address: wilfried.pacquentin@cea.fr (W. Pacquentin).
} 
In order to enrich the surface in chromium, it is possible to use its affinity with oxygen. Indeed at temperatures below $700{ }^{\circ} \mathrm{C}$ nickel diffusion through a $\mathrm{Cr}_{2} \mathrm{O}_{3}$ layer is much slower than $\mathrm{Cr}$ self-diffusion [23] so that during the first phase of high temperature oxidation chromium is oxidized to $\mathrm{Cr}_{2} \mathrm{O}_{3}$. But in the subsequent phase however the oxide content in $\mathrm{Ni}$ and $\mathrm{Fe}$ increases rapidly, as proved by Allen et al. [24]. This may lead to two main drawbacks : 1- the thicker the oxide layer, the more porous and less healing it becomes, 2- excessive diffusion of chromium towards the surface creates a sub-surface depleted zone which decreases the corrosion resistance properties [9]. Thus for our goal a controlled oxidation process limiting its extent so as to avoid structure degradation and subsurface depletion is necessary.

High temperature oxidation is classically performed using conventional heat treatments but laser processing of materials has extended the possibilities and is being increasingly used to optimize surface properties [25]. Among numerous techniques, laser surface melting (LSM) offers a significant potential for improvement of the corrosion behaviour [26-33]. For another application in the nuclear fuel cycle (storage of high level waste) LSM treatment of alloy 690 leads to an improved resistance to pitting corrosion due to chloride ions [27]. It has also been observed on chromium containing alloys that LSM can enrich the surface in chromium [28,34]. Analysis of this chromium enriched surface layer has revealed a significant amount of $\mathrm{Cr}_{2} \mathrm{O}_{3}$ on laser melted surfaces of Fe-based alloys [35] and Ni-based alloys [36]. Bao et al. [37,38] compared LSM and classical heat treatment on Ni-based alloys to produce controlled oxidation. They proved that laser treatment could reduce the subsurface chromium depletion and provide better healing properties to the oxide layer than classical heat treatment. Previous studies have shown that different LSM conditions lead to different surface modifications of the microstructure [26] and the chemical composition $[29,39]$. The laser pulse duration and duty-cycle have a direct influence on the resulting oxygen composition profile along the depth coordinate $[40,41]$.

In the specific case of a LSM process using low repetition rate nanosecond pulses at moderate average power, LSM only modifies the very surface properties of materials (molten depths are well within the micrometer range) while globally maintaining their bulk properties [42]. This process also results in high local transient temperatures $(>2000 \mathrm{~K})$, ultra-fast solidification $(>1 \mathrm{~m} / \mathrm{s})$ and ultra-high cooling rates $\left(10^{9} \mathrm{~K} / \mathrm{s}\right)$ which promote specific chemical and metallurgical changes. While controlled oxidations using classical heat treatments mainly involve diffusion mechanisms [43] the LSM process is suspected to promote specific vaporization of undesired elements like $\mathrm{Ni}$ and $\mathrm{Fe}$ (fractionation) [44-46] and/or segregation of chromium in the liquid phase $[47,48]$.

This state of the art motivated our search for an LSM treatment of alloy 690 leading to a reduction of the $\mathrm{Ni}$ release rate in the primary coolant medium of pressurized-water nuclear reactors. Performance assessment by measurement of the $\mathrm{Ni}$ release being a long procedure requiring specialized facilities with little availability such as the PETER loop of AREVA-ORANO [49] it can only be carried out for a small set of samples. Therefore in a first stage we developed the LSM treatment guided by the aim of substituting the usual outer Ni-containing spinel layer by a thin and continuous $\mathrm{Cr}_{2} \mathrm{O}_{3}$ layer maximally depleted in nickel while avoiding subsurface depletion in chromium. Here we report the influence of the LSM process parameters on the surface state of the treated samples, the selection of the best result and finally the performance obtained with the Ni release test. Various parameters were tested among which laser energy density and overlap ratio of laser impacts. The results were characterized using microscopic interferometry for surface roughness, SEM for microstructure and presence of inclusions, GDOES for elemental composition profile along the depth coordinate and XPS for $\mathrm{Cr}$ and $\mathrm{Ni}$ speciation at the extreme surface. The LSM parameter set leading to the best result was selected for the second stage in which the efficiency of this LSM treatment in terms of prevention of nickel release was assessed using a standard qualification test performed in the PETER loop [49]. Some additional LSM treatments were performed under an argon atmosphere in order to get more insight into the formation of the chromine layer.

Materials and methods are presented in Section 2. LSM treatments and sample surface analyses are described in Section 3. The nickel release performance test is reported in Section 4.

\section{Materials and methods}

\subsection{Sample preparation}

Alloy 690 was cast and annealed at $1071{ }^{\circ} \mathrm{C}$ for 30 min under hydrogen and water quenched. Then a $710^{\circ} \mathrm{C}-11 \mathrm{~h}$ thermal ageing was carried out, followed by air cooling. The chemical composition (Table 1) was analyzed using Inductively Coupled Plasma Optical Emission Spectrometry (ICP-OES).

The alloy plate was cut into samples of $2 \mathrm{~cm}^{2}$ for SEM and XPS analysis and $9 \mathrm{~cm}^{2}$ for GDOES analysis. Before the laser surface treatment the surface of the samples was grounded up to a 1200 grade SiC paper. This choice was made in order to increase the absorption of the incident laser beam and to control the uniformity of the sample surface. The samples were then submitted to ultrasonic cleaning and dried in air.

The reference samples for the $\mathrm{Ni}$ release experiment were electropolished.

After LSM treatment, some treated samples were observed in cross section. They were mechanically cut perpendicular to the LSM treated surface, mounted in a hot setting resin, grounded with SiC papers, polished with $1 \mu \mathrm{m}$ diamond paste and then with colloidal silica on a vibrating table.

Before introduction in the $\mathrm{Ni}$ release experiment all samples were rinced in deionised water.

\subsection{Laser surface melting setup and parameters}

LSM was carried out using an IPG Photonics ${ }^{\mathrm{TM}}$ pulsed Ytterbiumdoped fiber laser with $1060 \mathrm{~nm}$ wavelength, $140 \mathrm{~ns}$ FWHM pulse duration, $20 \mathrm{kHz}$ repetition rate and $20 \mathrm{~W}$ maximum average power. For the experiments reported in this study however the power never exceeded $16 \mathrm{~W}$. The laser beam was analyzed by a CCD camera. The laser beam impinges on the surface at right angle. At the sample surface the $1 / \mathrm{e}^{2}$ spot diameter $\mathrm{D}=2 \mathrm{R}$ is $125 \mu \mathrm{m}$ and the beam has a Gaussian energy distribution :

$\Phi(r)=\Phi_{\max } \exp \left(-\frac{2 r^{2}}{R^{2}}\right)$

where $\Phi(r)$ is the laser pulse energy density (in $\mathrm{J} / \mathrm{cm}^{2}$ ), $\Phi_{\max }=\Phi(0)$ is the energy density at the center of the laser spot, $r$ is the distance from the center (in $\mathrm{cm}$ ). After integration over the whole surface this yields:

$E=0.5 \pi R^{2} \Phi_{\max }$

where $\mathrm{E}$ is the energy per pulse (in $\mathrm{J}$ ). The average fluence over a disk of radius $a$ is

$\Phi_{\text {avg }}(a)=0.5\left(\frac{R}{a}\right)^{2}\left(1-\exp \left(-\frac{2 a^{2}}{R^{2}}\right)\right) \Phi_{\max }$

In the following for easier reference to the various beam conditions we use an equivalent beam description with a top-hat profile of same radius $\mathrm{R}$ and energy per pulse $E$ as those of the real gaussian beam. The fluence of this top-hat beam, denoted $\Phi_{t h}$, is thus given by

$\Phi_{t h}=\frac{E}{\pi R^{2}}=0.5 \Phi_{\max }$

and we call it simply "Energy density", expressed in $\mathrm{J} / \mathrm{cm}^{2}$. It has the following property: 
Table 1

Chemical composition of alloy 690 (wt. \%) used in present study (measured by ICP-OES).

\begin{tabular}{|c|c|c|c|c|c|c|c|c|c|}
\hline Elements & $\mathrm{Ni}$ & $\mathrm{Cr}$ & $\mathrm{Fe}$ & Mn & $\mathrm{Si}$ & $\mathrm{Cu}$ & C & $\mathrm{Ti}$ & $\mathrm{Al}$ \\
\hline wt $\% \pm 3 \%$ & 61.14 & 28.52 & 9.43 & 0.25 & 0.32 & 0.004 & 0.02 & 0.15 & 0.17 \\
\hline
\end{tabular}

$\Phi_{\text {th }} \approx 1.16 \Phi_{\text {avg }}(R) \approx \Phi_{\text {avg }}(0.893 R)$

The intensity time profile of a single laser pulse is somewhat complex with a main peak followed by a shoulder. We approximate it by a top-hat profile of $140 \mathrm{~ns}$ duration denoted $\tau$. Thus the maximum fluence and intensity of the pulse are related by $\Phi_{\max }=I_{\max } \tau$.

The average laser power was set to $7 \mathrm{~W}$ or $16 \mathrm{~W}$ depending on experiments, corresponding to an energy per pulse of $350 \mu \mathrm{J}$ and $800 \mu \mathrm{J}$ respectively. Thus the peak power varied between approximately 2500 $\mathrm{W}$ and $5700 \mathrm{~W}$ and the energy density $\Phi_{\text {th }}$ ranged between $2.9 \mathrm{~J} / \mathrm{cm}^{2}$ and $6.5 \mathrm{~J} / \mathrm{cm}^{2}$ (Table 2).

The entire sample surface was treated using an $\mathrm{X}-\mathrm{Y}$ galvanometric scanning system using the raster scan strategy illustrated on Fig. 1. The scanned area is a rectangle of dimensions $L_{x}$ and $L_{y}$ where $x$ is the direction of the raster lines. This scanned rectangle is centered on the sample but $L_{x}$ is significantly larger than the sample itself so as to avoid overheating at the sample edges when the sweep is stopped. For a given beam scanning velocity $\mathrm{V}$ the centers of two consecutive impacts in the same pass are separated by a distance

$d_{c i}=\frac{V}{f}$

where $f$ is the repetition rate of the laser pulses. The distance between two consecutive passes is set to that same distance $d_{c i}$ that separates two consecutive impacts in a given pass. The geometric pulse overlap is defined as

$O=1-\frac{d_{c i}}{2 R}$

where $\mathrm{R}$ is the beam radius as defined above. The scan parameters are chosen so as to vary the overlap between $50 \%$ and $90 \%$ in both directions (Fig. 1) and the beam velocity at the surface between $250 \mathrm{~mm} / \mathrm{s}$ and $1250 \mathrm{~mm} / \mathrm{s}$. Given that the sample dimensions are large compared to the beam size the number of impacts in a raster line is approximately equal to $L_{x} / d_{c i}$ and the number of raster lines to $L_{y} / d_{c i}$ so that the total number of impacts over the scanned surface is

$N=\frac{L_{x}}{d_{c i}} \frac{L_{y}}{d_{c i}}$

Since the surface of a single impact is $S_{\text {beam }}=\pi R^{2}$ the amplification coefficient $A$ (sometimes called "pulses-per-spot"), defined as the number of times that a given point of the surface is hit by the laser is

$A=\frac{N S_{\text {beam }}}{L_{x} L_{y}}=\pi\left(\frac{R}{d_{c i}}\right)^{2}=\frac{\pi}{4(1-O)^{2}}$

In our experiments these quantities take the following values:

\begin{tabular}{llll}
\hline Overlap $O$ & $50 \%$ & $70 \%$ & $90 \%$ \\
\hline Amplification coefficient $A$ & 3,1 & 8,7 & 78,5 \\
\hline
\end{tabular}

Table 2

Laser parameters.

\begin{tabular}{lll}
\hline Laser properties & & \\
\hline Frequency & 20 & $\mathrm{kHz}$ \\
Pulse duration & 140 & $\mathrm{~ns}$ \\
Wavelength & 1060 & $\mathrm{~nm}$ \\
Energy density & $2.9-6.5$ & $\mathrm{~J} / \mathrm{cm}^{2}$ \\
Peak power & $2500-5700$ & $\mathrm{~W}$ \\
Beam diameter & 125 & $\mu \mathrm{m}$ \\
\hline
\end{tabular}

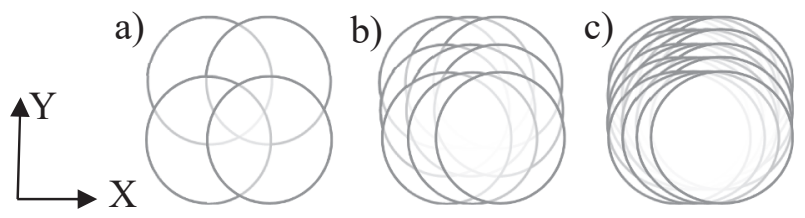

Fig. 1. Overlap patterns describing the positions of the laser impacts on the sample surface for an overlap rate of a) $50 \%$ - b) $70 \%$ - c) $90 \%$. Overlap is defined as the ratio of the distance between adjacent spot centers to the beam diameter. Only a few nearest neighbour laser impacts are represented. The raster scan sequence is intuitively illustrated by the solid and dashed lines. Neighbouring impacts are separated by $50 \mu$ s along $X$ and between $10 \mathrm{~ms}$ and $100 \mathrm{~ms}$ along $\mathrm{Y}$.

These values lend themselves to the following approximate description : with respect to the $50 \%$ overlap reference case, for an overlap of $70 \%$ a point of the surface receives about 2.8 times more laser energy and for an overlap of $90 \%$ it receives 25 times more laser energy. This simple model considers that a point at the surface is hit by the laser if it is located within a distance $\mathrm{R}$ from the center. The amplification coefficient $A$ does not account for the influence of the time interval between the laser pulses contributing to this accumulated energy, nor for the difference between a top-hat profile and the real beam profile. Anyway, its high sensitivity to the overlap is actually a true and important trend : $A$ increases very sharply when $O$ is varied between an overlap of $70 \%$ (700 impacts $/ \mathrm{mm}^{2}$ ) and $90 \%$ (6400 impacts $/ \mathrm{mm}^{2}$ ) [35].

As for the evolution along time, the delay between two neighbouring impacts is equal to the pulse period $1 / f=50 \mu$ s if they belong to the same laser pass. If they belong to two different laser passes it is equal to $L_{x} / V$, ranging between about $30 \mathrm{~ms}$ and $160 \mathrm{~ms}$ depending on the experiments. The thermal cycles imposed to the surface depend on both these time constants.

In order to optimize the LSM treatment two laser parameters were specifically considered: (1) the laser energy density $\left(\mathrm{J} / \mathrm{cm}^{2}\right)$ which mostly influences the peak surface temperature and (2) the overlap (\%) which affects both the lifetime of the melt pool and the number of cyclic heating [50].

In addition to these laser parameters, while most samples were treated in ambiant air some other samples were treated under an argon flow $(100 \mathrm{~mL} / \mathrm{min})$. The samples were enclosed in an airtight aluminum cell, equipped with a crystalline quartz window transparent to the laser beam. The vaporized particles were picked up by the gas flow and collected on a cellulose filter paper placed at the cell exit for further elemental analysis as described below.

\subsection{Surface analysis}

Surface morphology after LSM was recorded with a white light interferometer (Bruker ContourGT1). Roughness is deduced using image processing with the Vision64 software with a sub-nanometer vertical resolution and a sub-micron lateral resolution. Microstructural observations are carried out with a SEM-FEG (Jeol 7000F) equipped with EDS analysis.

After LSM treatment, the surface elemental composition was analyzed by a Horiba Jobin Yvon GDOES. LSM treated surfaces were first submitted to a plasma cleaning at $120 \mathrm{~Pa}$ and $2 \mathrm{~W}$ for possible desorption of water molecules and organic traces and then analyzed 
atomic layer by atomic layer up to $15 \mu \mathrm{m}$ depth thanks to argon-ion beam sputtering. The composition is averaged over a $4 \mathrm{~mm}$ diameter area. Escobar Galindo et al. [51] have proved that this elemental analysis is accurate although depth resolution degrades linearly with depth due to sputtering effects. Since in our case the composition evolves over less than a few hundred nanometers our results are not affected by this problem. If the sample surface is not flat to the nanometer scale the signal arising from any particle, deposit or precipitate present at the surface is "diluted" in the composition profile. In such a case a careful reading of the composition profile of the elements present in the inclusions covering the surface is required. Nevertheless, each of the presented values is an average over five GDOES spectra recorded at differents places of a given sample corresponding to a given set of laser treatment parameters.

We define the oxide thickness here as the depth where the oxygen content reaches one third of the maximum oxygen concentration. The peak value $(\mathrm{Cr} / \mathrm{Ni}) \mathrm{max}$ is used to compare the chromium enrichment versus nickel depletion. Oxide thickness and $(\mathrm{Cr} / \mathrm{Ni})$ max are averaged over five to ten GDOES spectra per laser treatment conditions.

The oxidation state of nickel and chromium was determined using a ThermoScientific Escalab 250xi XPS spectrometer. The XPS-analyzed zone is a cylinder of $900 \mu \mathrm{m}$ diameter and a few nanometers depth.

The filters containing the aerosols collected during treatments under argon were dissolved in nitric acid and the solution was analyzed by Inductively Coupled Plasma Optical Emission Spectrometry (ICP- OES).

This whole set of surface-analysis techniques allowed us to compare the $\mathrm{Cr} / \mathrm{Ni}$ ratios for all the LSM conditions considered.

\subsection{The PETER primary coolant loop test facility}

The high temperature and high pressure titanium micro loop named PETER [49] is a research facility designed to measure the kinetics of cation release of tubes in the primary chemistry environment [2]. It consists in exposing sample surfaces to a simulated primary medium free of metallic cations. The composition of this medium made of several compounds dissolved in water is given in Table 3. In turn, the metallic cations analyzed in the primary medium are only produced by the corrosion process: nickel release depends on the solubility of nickel corrosion products and the substantial dissolution of nickel metal deposits [7].

In order to assess the effect of the laser treatment, twelve flat samples were introduced in the loop: six raw samples and six samples laser treated on their two largest sides. There is a specific test canal for each sample, with individual analysis circuitry.

The standard test procedure consists of three phases: a heating phase, an isothermal main stage and a cooling phase (Fig. 2). The pressure of the primary medium was set to $15.5 \mathrm{MPa}$ absolute pressure. The temperature was raised to $300^{\circ} \mathrm{C}$ with a temperature ramp of approximately $0.6{ }^{\circ} \mathrm{C} / \mathrm{min}$ and was then slowly adjusted to $325^{\circ} \mathrm{C}$ within the next $16 \mathrm{~h}$ ("heating phase"). Then temperature and pressure were kept constant for $650 \mathrm{~h}$ ("main stage"). Finally temperature and pressure were decreased back to ambient conditions in about $16 \mathrm{~h}$ ("cooling phase").

The amount of metallic cations released during the heating phase was measured as a function of time by analyzing the composition of the fluid and the same was done for the plateau and the cooling phases. The

Table 3

Chemical composition of the simulated primary medium running in PETER.

\begin{tabular}{ll}
\hline Element & Concentration $(\mathrm{mg} / \mathrm{kg})$ \\
\hline $\mathrm{Li}$ & 1.75 \\
$\mathrm{~B}$ & 993 \\
$\mathrm{Cl}^{-}$ & $>0.02$ \\
$\mathrm{SO}_{4}^{2-}$ & $>0.02$ \\
$\quad$ water & (balance) \\
\hline
\end{tabular}

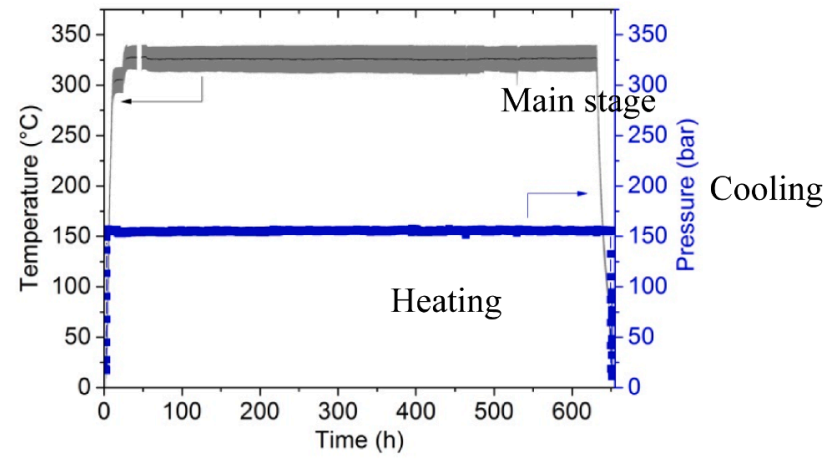

Fig. 2. Temperature and pressure in the simulated primary coolant loop vs. time.

online measurement technique is based on polarography (Hanging Mercury Drop Electrode) and ICP-OES. During the main stage the composition analysis was performed every day. This measurement gave us access to metallic cation release kinetics. Direct cation release of a chemical element is calculated from the product of its concentration by the flow rate in the test section and divided by the normalized surface of the sample. Direct cation releases are expressed in $\mathrm{mg} / \mathrm{dm}^{2} / \mathrm{h}$ and the cumulative cation release in $\mu \mathrm{g} / \mathrm{dm}^{2}$.

\section{Laser surface melting treatment}

In this Section we characterize the effect of the LSM treatment in terms of surface morphology, depth profile, microstructure and chemical composition of the outer surface layers. The goal is to identify the best LSM parameter set in terms of formation of a continuous chromine layer depleted in nickel at the outer surface, without $\mathrm{Cr}$ depletion in the bulk.

\subsection{Surface morphology after laser surface melting}

\subsubsection{Single spot}

The treatment of an extended surface proceeds by scanning a pulsed beam with overlap of impacts in both directions. To better control the treatment of extended surfaces it is necessary to know the effect of a single laser shot so as to identify the parameter ranges leading to the various regimes such as simple heating, fusion, vaporisation and ablation. Fig. 3 shows the relief of the surface after a single laser spot with laser energy density $6.5 \mathrm{~J} / \mathrm{cm}^{2}$ observed using the white light interferometer. In the central zone (1) a vertical depression is present. It is surrounded by an external ring (2) positioned above the initial surface, itself surrounded by a molten zone (3) featuring a modified surface and smoothed scratches compared to the rest (4) of the sample. The presence of the central crater and the ring is consistent with a scenario in which evaporation occurs during the laser pulse and induces liquid motion due to the recoil effect of the vapor pressure pushing the liquid away from the laser impact center (piston effect). The ring itself is formed when the radial centrifugal fluid flow meets the centripetal solidification front. It may also be stabilized by surface tension [52]. Note that other driving forces may predominate when a high temporal rate of laser impacts induces locally a thermal evolution over longer time scales - which is not the effect searched for in this study.

\subsubsection{LSM treatments of extended zones}

Fig. 4 shows SEM micrographs of the surface of the samples after three LSM treatments for which various sets of laser energy density and overlap.

At low energy density $\left(2.9 \mathrm{~J} / \mathrm{cm}^{2}\right)$ and for $50 \%$ overlap a good uniformity of the surface topography was obtained (no crater, no ring) because vaporization effects were reduced (Fig. 4a). Ti(C,N) precipitates 


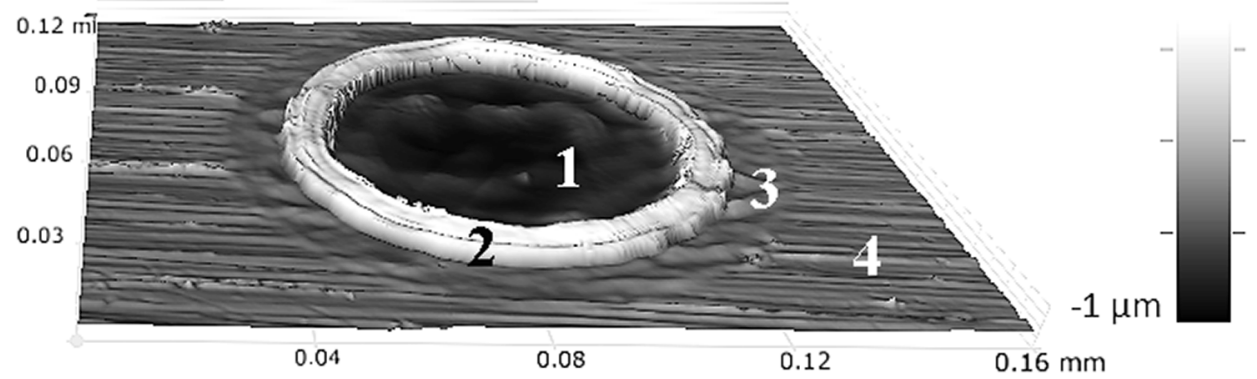

Fig. 3. 3D representation of a laser impact with laser energy density $6.5 \mathrm{~J} / \mathrm{cm}^{2}$ observed with a white light interferometer : (1) central zone displaying a vertical depression, (2) external ring positioned above the initial surface level, (3) boundary of the molten zone, (4) outer surface.

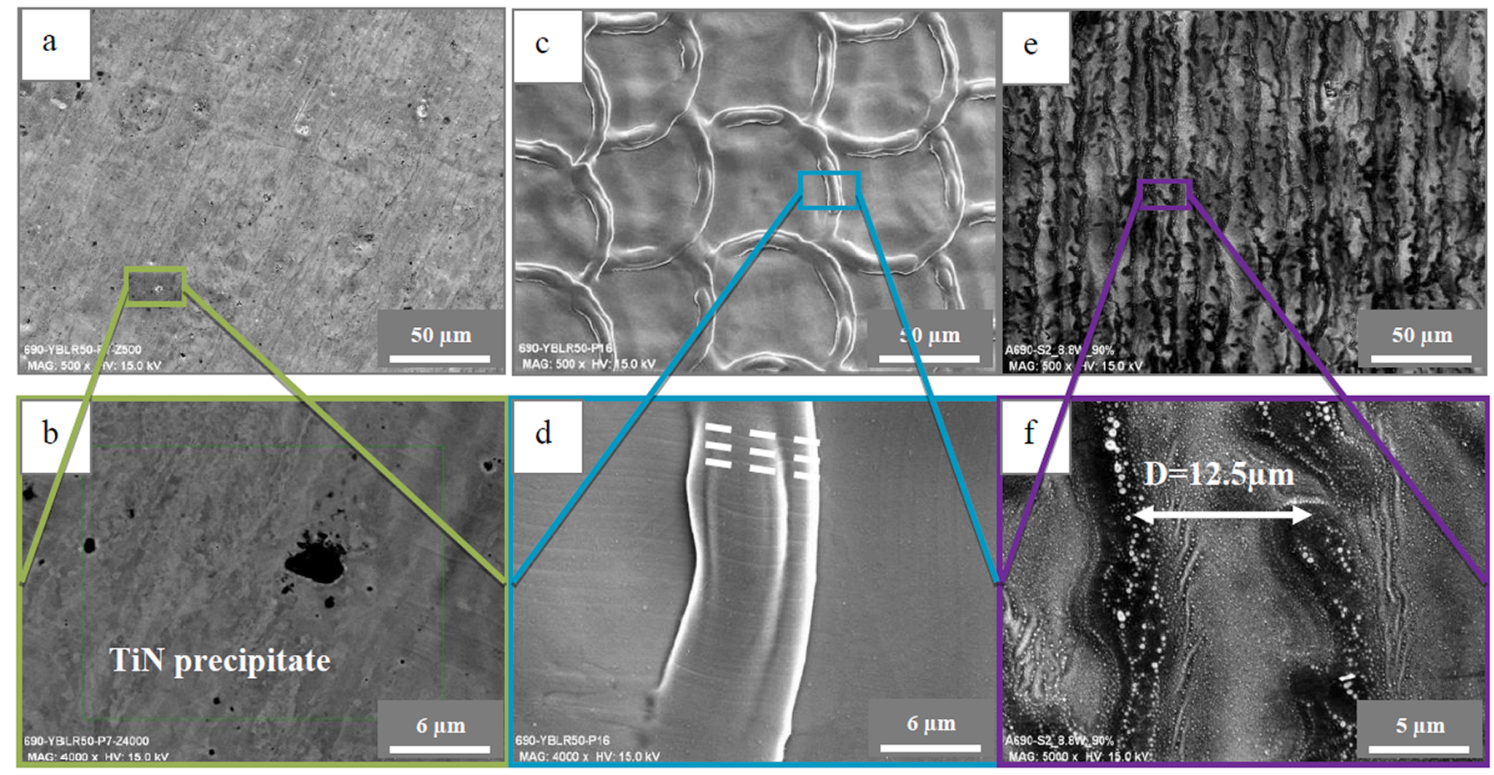

Fig. 4. SEM micrographs of the laser treated surfaces. (a),(b) $2.9 \mathrm{~J} / \mathrm{cm}^{2}-50 \%$ overlap. (c),(d) $6.5 \mathrm{~J} / \mathrm{cm}^{2}-50 \%$ overlap . (e), (f) $3.6 \mathrm{~J} / \mathrm{cm}^{2}-90 \%$ overlap. Fig. $4 \mathrm{~b}$ (resp 4d, 4f) is a zoom into the rectangle shown in Fig. 4a (resp 4c, 4e).

remained on the upper surface after melting (Fig. 4b) and were also detected by EDS analysis.

Fig. $4 \mathrm{c}$ and $4 \mathrm{~d}$ exhibit micrographs of the surface of the samples treated at $6.5 \mathrm{~J} / \mathrm{cm}^{2}$ laser energy density and $50 \%$ overlap. The laser spots rings were clearly superimposed. Ti containing precipitates could no longer be seen. We think they were dissolved in the fusion zone but they may also have evaporated. Similar results were observed for laser energy densities ranging between $4.3 \mathrm{~J} / \mathrm{cm}^{2}$ and $6.5 \mathrm{~J} / \mathrm{cm}^{2}$ and $50 \%$ overlap. Since the melting temperatures of $\mathrm{TiC}$ and $\mathrm{TiN}$ are respectively $\mathrm{Tm}=3067{ }^{\circ} \mathrm{C}$ and $\mathrm{Tm}=2950^{\circ} \mathrm{C}[53]$ their disappearance may indicate that the temperature went up beyond these thresholds for laser energy densities above $4.3 \mathrm{~J} / \mathrm{cm}^{2}$. At higher magnification some features perpendicular to the external ring (i.e. radially from the centre of the meltpool) become visible (Fig. 4d). We interpret them as slip bands as similar bands have already been observed on this material after a $\mathrm{CO} 2$ laser treatment. According to Lim et al. [47] these planes belong to the (111) family since A690 has a face-centered cubic structure and they may be due to severe thermal tensile stress generated during fast solidification.

For overlap above $90 \%$, whatever the laser energy density, periodic lines spaced by $12.5 \mu \mathrm{m}$ were visible. Fig. $4 \mathrm{e}$ and $\mathrm{f}$ show the case of a sample treated with a $3.6 \mathrm{~J} / \mathrm{cm}^{2}$ laser energy density. The $12.5 \mu \mathrm{m}$ distance corresponds exactly to the distance imposed between the scanning lines $\left(d_{c i}=V / f=(0.25 \mathrm{~m} / \mathrm{s}) /(20 \mathrm{kHz})\right)$. The oxide layer is not continuous and rather crumbly or even powdery.
All these results show that the superimposition of laser impacts at laser energy density higher than $4.3 \mathrm{~J} / \mathrm{cm}^{2}$ leads to a rougher surface with the presence of numerous ridges. After LSM, roughness was shown to increase from $\mathrm{Ra}=0.3 \mu \mathrm{m}$ to $\mathrm{Ra}=0.9 \mu \mathrm{m}$, the latter values being averages over measurements made at 5 different locations with the method described in Section 2.3. This roughening tends to increase the surface area exposed to the primary medium, which in turn can be expected to result in a higher nickel release, proportionally to the surface change. The influence of surface state on nickel release was indeed evidenced by Kim et al [13] who showed that electropolishing leads to a reduction in nickel release by a factor 4 compared to a shot peening treatment and who attributed the result to a change in the metal-ion transfer depending on the residual stress in the metallic surface layer.

As a conclusion, based on the criterion of a continuous and defectfree surface morphology, the suitable LSM parameter range is limited to laser energy densities below $6.5 \mathrm{~J} / \mathrm{cm}^{2}$ and overlap ratios strictly below $90 \%$.

Next we describe the depth profile and the microstructure of the surface layer created by the LSM treatment.

\subsection{Cross sectional observations}

Fig. 5 shows the SEM cross section of a laser treated sample with 3.6 $\mathrm{J} / \mathrm{cm}^{2}$ laser energy density and $70 \%$ overlap. Next to the surface and within a depth varying between about $1 \mu \mathrm{m}$ and $2 \mu \mathrm{m}$ no grain boundary 


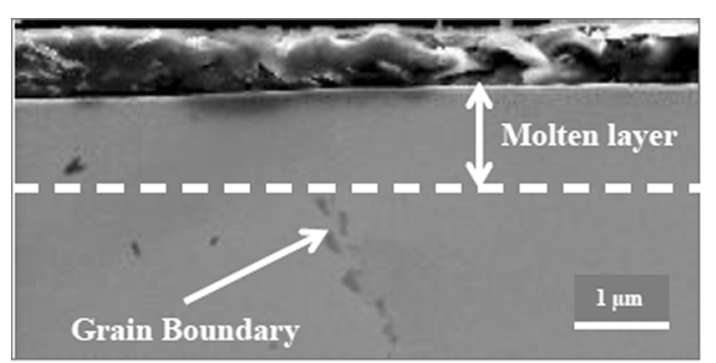

Fig. 5. Cross section of a LSM treated surface with $3.6 \mathrm{~J} / \mathrm{cm}^{2}$ and $70 \%$ overlap.

could be detected. Therefore the zone going from the surface up to the first location of grain boundaries was interpreted as the molten layer, as approximately shown by a white dashed line on Fig. 5 . We note that for the lower values of overlap up to about $70 \%$ the oxide layer thickness (determined by GDOES as described below) was too thin $(<10 \mathrm{~nm})$ to be detectable with SEM.

The absence of grain boundaries just underneath the surface suggests a planar front solidification mode. According to Mokadem [54] such a solidification mode is possible at very high solidification rates (in the $\mathrm{m}$ / $\mathrm{s}$ range). For our LSM conditions, a Vs $=1.5 \mathrm{~m} / \mathrm{s}$ liquid/solid front velocity was calculated using a numerical model presented elsewhere [52], which confirms the likeliness of such a planar solidification front.

When overlap reaches $90 \%$ the molten layer is strongly changed with respect to cases with overlap lower than $90 \%$ (Fig. 6). The thickness of the molten layer reaches $280 \mathrm{~nm}$ (Fig. 6a). While the molten layer is very homogeneous for less than $90 \%$ overlap, sub-layers may be observed for $90 \%$ overlap (Fig. $6 \mathrm{~b}$ ):

1- A chromium-rich oxide layer becomes visible on the cross section.

2- Nanometric white spheres present in the uppermost part of this oxide layer and mostly composed of metallic nickel are embedded in a chromium-rich matrix.

2- Underneath the spheres the oxide layer is continuous.

3- Below the oxide layer, some chromium oxide precipitates are detectable in the metallic molten zone.

The composition of the white spheres and the precipitates was measured using transmission electron microscopy because their small size made it inaccessible to SEM-EDS. Thus their identification is beyond doubt even though their formation mechanism remains partly unclear and we can only suggest an interpretation. This particular microstructure is attributed to the short period of thermal cycling inducing a more pronounced reheating effect, with the formation of sub-layers in the laser melted layer. During high rate cooling, diffusion of oxygen into the melt pool leads to formation of nano-precipitates of $\mathrm{Cr}_{2} \mathrm{O}_{3}$ because of their high solidification temperature $\left(2265^{\circ} \mathrm{C}\right.$ [55]) compared to those of alloy $690\left(1350{ }^{\circ} \mathrm{C}\right.$ [56]) and pure nickel $\left(1200{ }^{\circ} \mathrm{C}\right.$ [57]). Then the alloy, depleted in chromium, solidifies and nickel at the surface, depleted in oxygen, solidifies in spheres, trapped in chromium oxides.

As a conclusion, cross-sectional observations clearly lead to a limit in the overlap ratio well below $90 \%$, while a regime such as $3.6 \mathrm{~J} / \mathrm{cm}^{2}$ laser energy and $70 \%$ overlap appears favourable.

Next we address the average chemical composition of the outer layer resulting from the LSM treatment.

\subsection{Chemical analysis}

Fig. 7 shows the elemental composition profile of various chemical elements from the surface to the bulk of the material, measured using GDOES as described in Section 2.3. In the raw material (Fig. 7a) beyond $0.02 \mu \mathrm{m}$ away from the surface the chemical composition corresponds to the overall (bulk) composition of the material ( $\sim 60 \mathrm{wt} \% \mathrm{Ni}, \sim 30 \mathrm{wt} \%$ $\mathrm{Cr}$ and $\sim 10$.wt $\%$ Fe, see Table 1 ). The oxygen content is less than $5 \mathrm{wt} \%$. Within the first $10 \mathrm{~nm}$ below the surface the fraction of Ni decreases while that of oxygen increases. The oxide layer thickness (as defined in Section 2.3 with an arbitrary $1 / 3$ oxygen content criterion) is estimated to be less than $0.01 \mu \mathrm{m}$. LSM significantly modifies these profiles. Fig. $7 \mathrm{~b}$ displays the profiles after LSM at $3.6 \mathrm{~J} / \mathrm{cm}^{2}$ laser energy density and $70 \%$ overlap. Near the surface the relative $\mathrm{Ni}$ content is drastically reduced so as to nearly vanish at the surface while the oxygen content steeply increases. The Fe content follows the same qualitative trend as that of $\mathrm{Ni}$. The $\mathrm{Cr}$ content displays a non-monotonous profile. It slightly increases at intermediate depth and decreases closer to the surface. As a result, the oxygen and chromium fractions are higher just underneath the surface than in the bulk whereas the trend is opposite for $\mathrm{Ni}$ and Fe. Fig. $7 \mathrm{~b}$ shows a chromium and oxygen content more than twice higher at the surface than at depth. This difference in chemical composition between the surface and the bulk allowed to identify the presence of an oxide layer enriched in $\mathrm{Cr}$. Given that $\mathrm{Cr}$ depletion in a sublayer would be a strict criterion for rejection of this LSM parameter set it is important to note that here the $\mathrm{Cr}$ content remains sufficiently high everywhere.

Chromium enrichment at the surface, whereby the $\mathrm{Cr}$ content increased up to $40 \mathrm{wt} \%$ compared of $30 \mathrm{wt} \%$ in the raw material, was observed for all the laser parameters. In parallel the Ni content was generally reduced below $10 \mathrm{wt} \%$ and the Fe content below $1 \mathrm{wt} \%$.

The maximum value of the $\mathrm{Cr} / \mathrm{Ni}$ ratio is denoted $(\mathrm{Cr} / \mathrm{Ni}) \max$ and is averaged over five to ten GDOES profiles.

The ratio of the Cr weight fraction to the Ni one is also plotted as " $\mathrm{Cr}$ / a)

b)

)

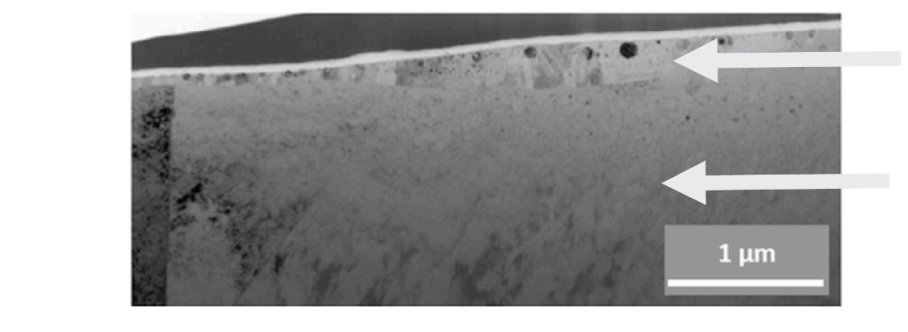

\section{Molten zone}

\section{Substrate}



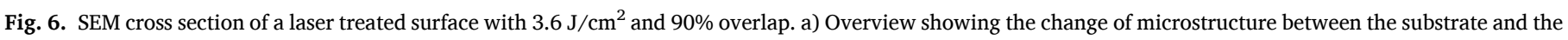
molten zone. b) Zoom on the molten zone. Sublayers are clearly visible and have been chemically analyzed. 


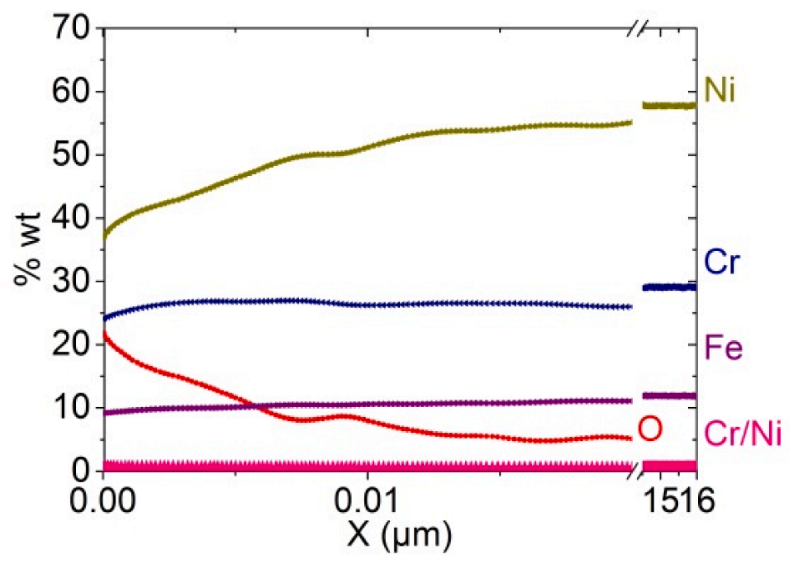

a)

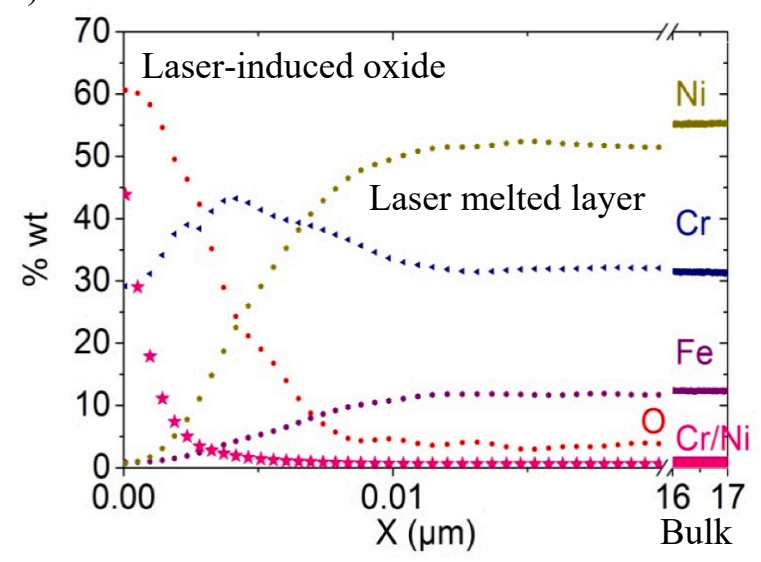

b)

Fig. 7. GDOES chemical composition profiles along depth for $\mathrm{Ni}, \mathrm{Cr}, \mathrm{Fe}, \mathrm{O}$ and the ratio of the $\mathrm{Cr}$ content over the $\mathrm{Ni}$ content. The dimensionless $\mathrm{Cr} / \mathrm{Ni}$ values should be read using the labels on the vertical axis. a) Raw surface. b) Laser treated surface (treatment conditions: $3.6 \mathrm{~J} / \mathrm{cm}^{2}$ and $70 \%$ overlap).

$\mathrm{Ni}$ " in Fig. 7a and b using the same vertical axis labels as for the weight fractions themselves. This quantity is an indicator of the chromium enrichment due to LSM. We used its value over the first nanometer and averaged over five to ten GDOES profiles, denoted " $\mathrm{Cr} / \mathrm{Ni})_{\max }$ " in what follows, as a criterion for selection of the samples to be submitted to the corrosion test in the primary coolant loop. Dispersion of the results is calculated as the rms deviation associated with this averaging, i.e. over the five to ten GDOES profiles recorded at differents points of a given sample.

Fig. 8 displays $(\mathrm{Cr} / \mathrm{Ni})_{\max }$ as a function of fluence for $50 \%$ overlap. $\mathrm{Cr}$ enrichment appears in this $50 \%$ overlap case as a smooth and monotonously decreasing function of the laser energy density.

Fig. 9 displays the oxide layer thickness (circles) as a function of overlap for $3.6 \mathrm{~J} / \mathrm{cm}^{2}$ laser energy density. Up to $80 \%$ overlap the thickness varies between about 8 and $15 \mathrm{~nm}$, increasing slighly with overlap, while the surface roughness and composition vary smoothly. Fig. 9 also displays the composition ratio $(\mathrm{Cr} / \mathrm{Ni})_{\max }$ (pentagons). The large variations of this ratio reflect the fact that the $\mathrm{Ni}$ content at the extreme surface goes down to almost zero for some LSM parameter sets. For $90 \%$ overlap the layer becomes much thicker, reaching $100 \mathrm{~nm}$ and more - as some GDOES profiles revealed a $200 \mathrm{~nm}$ to $300 \mathrm{~nm}$ thickness. In spite of the increased roughness (cf Fig. 4e) and the associated variations in local composition the LSM performance in terms of $(\mathrm{Cr} / \mathrm{Ni})_{\max }$ remains rather small everywhere on the surface in this $90 \%$ overlap case. The dispersion of the GDOES measurements performed on a given sample remains small throughout the range of overlap ratio, which shows that the surface composition of a given sample is rather homogeneous. The maximum values of $(\mathrm{Cr} / \mathrm{Ni})_{\max }$ between 20 and 40 are

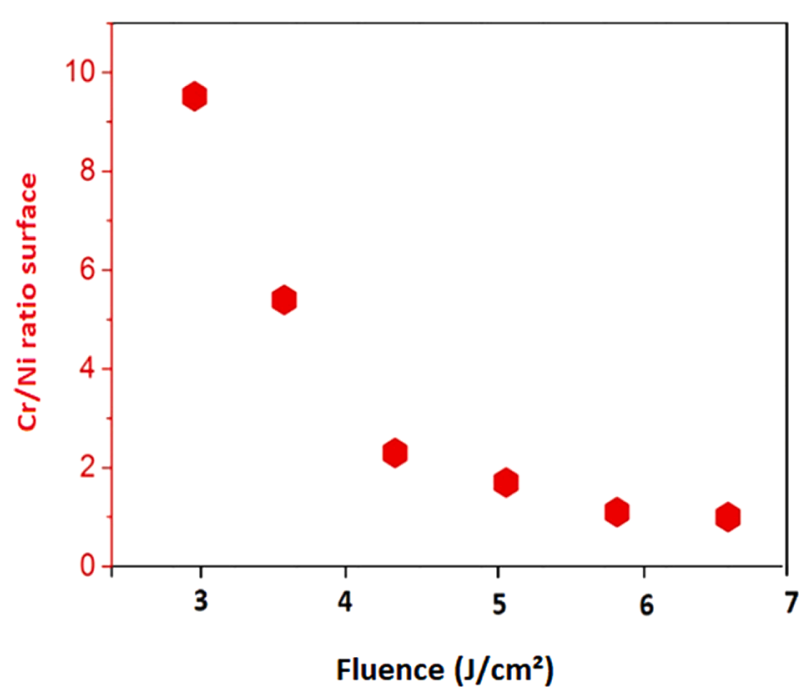

Fig. 8. $(\mathrm{Cr} / \mathrm{Ni})_{\max }$ vs. fluence for $50 \%$ overlap. Dispersion of the results is represented by the dot size.

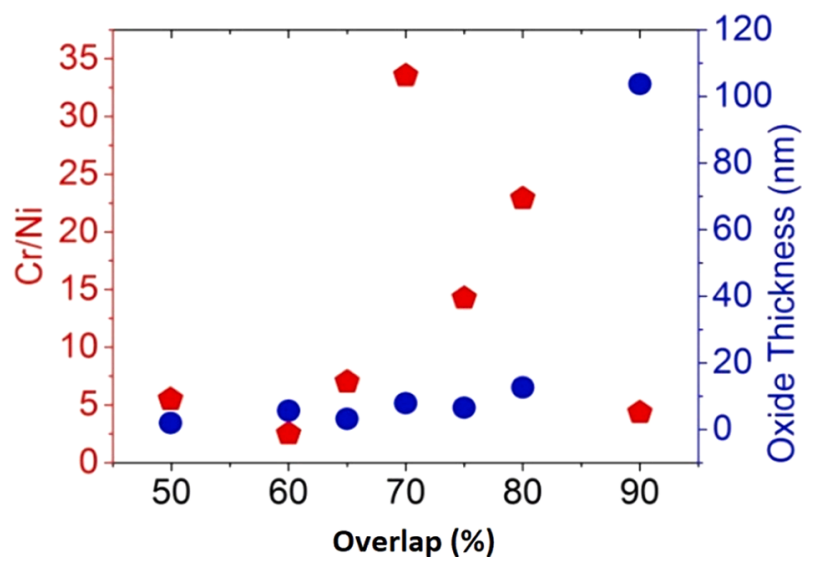

Fig. 9. Oxide thickness (circles) and $(\mathrm{Cr} / \mathrm{Ni})_{\max }$ (pentagons) versus overlap at $3.6 \mathrm{~J} / \mathrm{cm}^{2}$ laser fluence. Dispersion of the results is represented by the symbol size.

found for overlaps around $70 \%$.

In order to both confirm the GDOES results and identify the oxidation state of the elements at the extreme surface some samples were analyzed using XPS. We chose a sample that had a ratio $(\mathrm{Cr} / \mathrm{Ni})_{\max }$ of 35 and had been treated at $3.6 \mathrm{~J} / \mathrm{cm}^{2}$ and $70 \%$ overlap. The corresponding oxide layer thickness was around $8 \mathrm{~nm}$ and the associated surface was very smooth $(\mathrm{Ra}=0.4 \mu \mathrm{m})$. Fig. 10 shows the XPS signal which originates from the $10 \mathrm{~nm}$ sub-surface layer. Both the untreated sample and the LSM treated sample are analyzed. Metallic contributions of $\mathrm{Cr}$ at $574,4 \mathrm{eV}$ and $\mathrm{Ni}$ at $852.8 \mathrm{eV}$ are visible on both raw and laser-treated surfaces, indicating that the thickness of the oxide layer is less than about $6 \mathrm{~nm}$. The spectra show a significant reduction of the Ni content after laser surface treatment and a complete disappearance of oxidized nickel, in sharp contrast with the opposite trends for $\mathrm{Cr}$ for which both the overall content and the oxidized state increase.

Assuming that only $\mathrm{Ni}$ and $\mathrm{Cr}$ are present and that, consistently with the SDL results, the oxide layer is the external one, more quantitative estimates can be obtained from the peak intensity ratios as in Table 4 . Whereas the raw surface contains $75 \%$ chromium in the oxide contribution the LSM-induced oxide layer is fully composed of chromium. The $\mathrm{Cr}$ content in the metallic contribution is almost twice higher in the laser treated surface than in the raw material surface. This LSM induced chromium enrichment under the oxide layer is consistent with the 

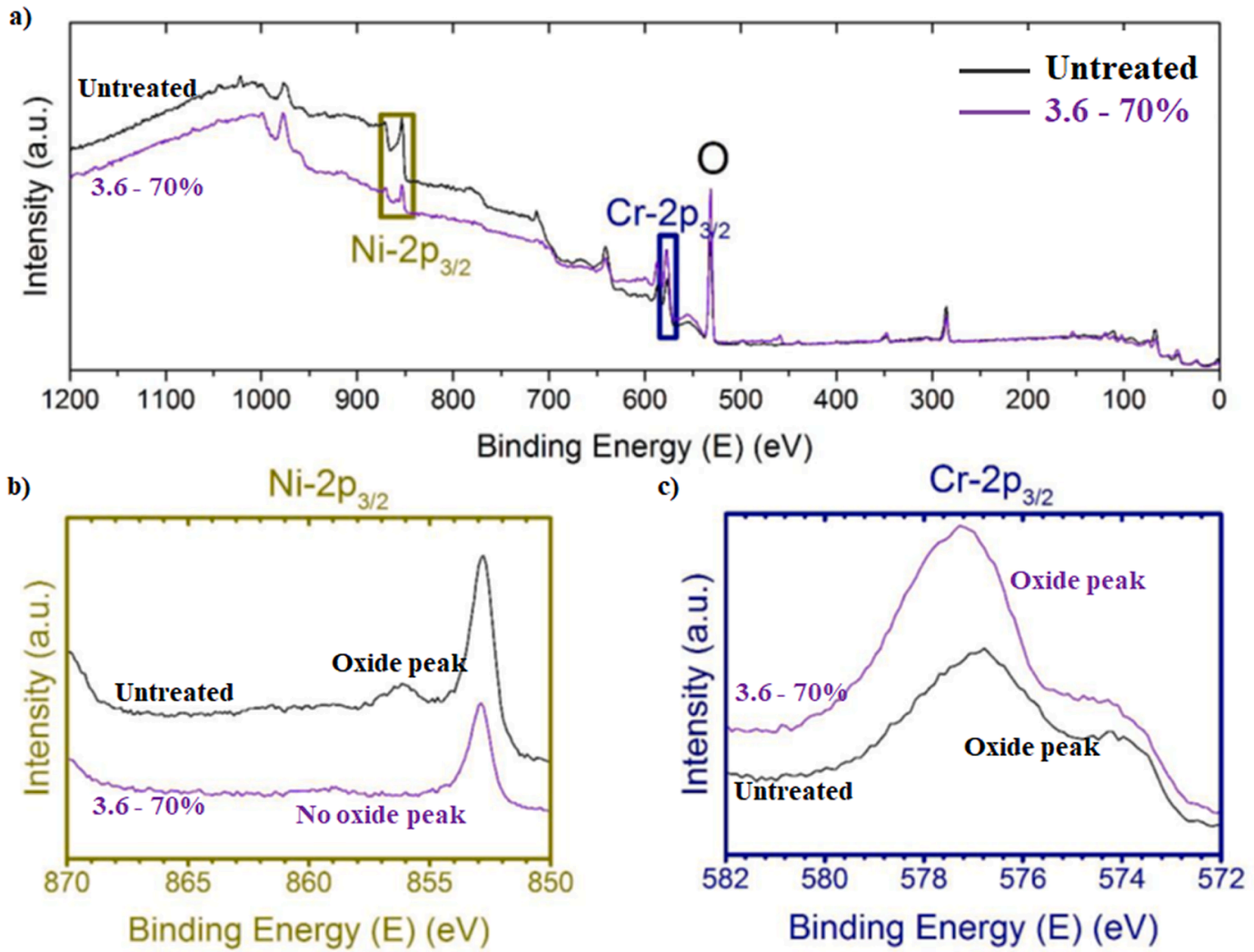

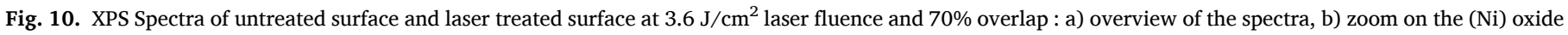
peak, c) zoom on the $(\mathrm{Cr})$ oxide peak.

Table 4

Elemental composition from XPS analyses before (denoted "Raw") and after a LSM treatment. Only $\mathrm{Ni}$ and $\mathrm{Cr}$ are analyzed. Oxides and metallic contributions are analyzed separately and reported as ratios of integrated peak intensities using at $\% \mathrm{Ni}+$ at $\% \mathrm{Cr}=100 \%$. Treatment conditions: $3.6 \mathrm{~J} / \mathrm{cm}^{2}$ and $70 \%$ overlap.

\begin{tabular}{lll}
\hline Raw & Oxide & Metal \\
\hline $\mathrm{Ni}$ & 25 & 68 \\
$\mathrm{Cr}$ & 75 & 32 \\
Laser treated & Oxide & Metal \\
$\mathrm{Ni}$ & 0 & 45 \\
$\mathrm{Cr}$ & 100 & 55 \\
\hline
\end{tabular}

concentration profiles of Fig. $7 \mathrm{~b}$ at around $8 \mathrm{~nm}$ depth. The relative constancy of the chromium concentration under the oxide layer, visible in Fig. $7 \mathrm{~b}$ at depths beyond $12 \mathrm{~nm}$, as compared to other types of surface treatment whereby the subsurface is severely Cr-depleted, is a quite important favourable feature of this LSM treatment. Indeed in case of accidental cracking of the top surface layer a reservoir of metallic chromium is available for further oxidation and surface passivation recovery.

\subsection{Selective vaporization during LSM under argon}

In order to investigate the influence of the ambient atmosphere on the growth of the $\mathrm{Cr}_{2} \mathrm{O}_{3}$ oxide layer as well as the composition of the material vaporized during the LSM treatment, searching in particular for a possible selective vaporization of elements, some complementary experiments were carried out as described in Section 2.3 under an argon atmosphere. The argon gas flow sweeping the surface picks up all the aerosols which are then collected by a filter made of cellulose nitrate at the cell exit. The samples were treated in the same conditions than under air with laser energy densities between $2.9 \mathrm{~J} / \mathrm{cm}^{2}$ and $6.5 \mathrm{~J} / \mathrm{cm}^{2}$ and 50 $\%, 70 \%$ and $90 \%$ overlaps. For ranges of pulse duration and fluence such as ours the laser-matter interaction mechanisms remain close to local thermodynamic equilibrium i.e. based on heat conduction, melting and evaporation, as opposed to shorter pulses in the picosecond regime or below, for which ablation driven by phase explosion occurs [58].

SEM analysis showed the same surface topography for laser treatments under air or argon.

GDOES spectra showed about the same composition profiles vs depth as under air, including an enrichment in chromium and a depletion in nickel and iron over the first ten nanometers as found for LSM under air. The iron content over the first few nanometers was found lower under argon than under air. Indeed under argon it is almost always below the detection limit.

The $(\mathrm{Cr} / \mathrm{Ni})_{\max }$ ratio was generally similar under argon and under air except that values above 8 only occurred with air, indicating a possible influence of oxygen on the chromium content at the extreme surface for these treatments. The oxide layer thickness was generally similar under argon and under air, except that it always remained below $25 \mathrm{~nm}$. The up to $100 \mathrm{~nm}$ thick layers (see example on Fig. 9) were only obtained under air. In conclusion, excluding the $90 \%$ overlap case for which the behaviour is specific, ambient oxygen gas may be quite favourable to $\mathrm{Cr}$ enrichment at the extreme surface even though it does not play a major role in the oxide layer thickness.

Aerosols collected on filters were analyzed using ICP-OES (Fig. 11). For $90 \%$ overlap the iron content of aerosols was that of bulk alloy 690 (Fig. 11a). Such a result is characteristic of a regime of strong evaporation or ablation for which the composition in the bulk and the removed material are identical. The $\mathrm{Cr} / \mathrm{Ni}$ ratio (Fig. 11b) however varies significantly over the laser energy density range, showing a preferential vaporization of chromium at low laser power. For $50 \%$ overlap the filters contained about $20 \mathrm{wt} \% \mathrm{Fe}$, which is twice higher than in the bulk material. They also collected chromium and nickel with 
a)

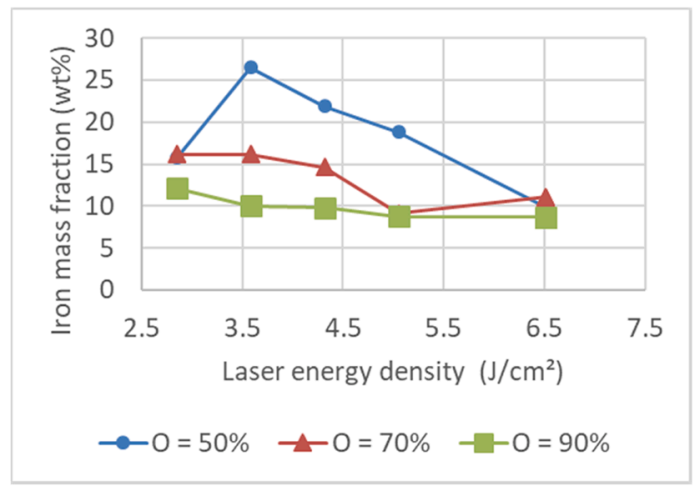

b)

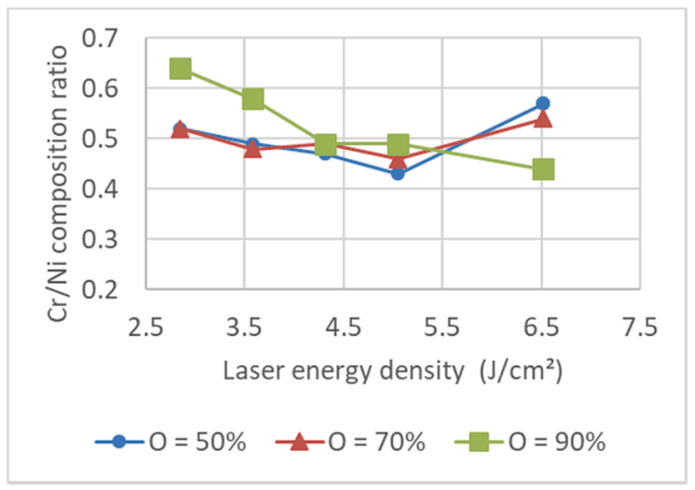

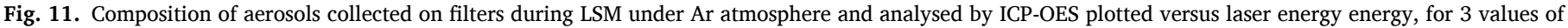
overlap $O$. Each data point is an average over 6 experiments. a) Iron weight fraction. b) Chromium to nickel weight fraction ratio $\mathrm{Cr} / \mathrm{Ni}$.

Gr $-\mathrm{Ni}=0.50 \pm 0.05$, similar to that of the bulk material. These results point to the existence of a transition regime between strong and weak evaporation located somewhere around the central values of laser energy density and overlap investigated in this study. For the lower amounts of evaporated material the composition of the aerosols reflects both the relative vapour pressure of the elements and their affinity to oxygen.

The high $\mathrm{Cr} / \mathrm{Ni}$ ratio of 0.64 measured in the aerosol composition for low fluence and $90 \%$ overlap is consistent with the low $(\mathrm{Cr} / \mathrm{Ni})_{\max }$ of the sample surface obtained in the same LSM conditions (see Fig. 9 and Section 2.3). Given that chromium metal is about twice as volatile as Fe and $\mathrm{Ni}$ this points to a possible interpretation whereby selective chromium evaporation is induced in this particular case by the prolonged heating effect of the many laser shots impacting the same location.

Except for this special case of $90 \%$ overlap, the $\mathrm{Cr} / \mathrm{Ni}$ content of the aerosols remained always close to that of the bulk material. Thus the observed chromium enrichment at the extreme surface is only due to a spatial redistribution of the elements within the condensed phase.

\subsection{Discussion}

As stated in the Introduction our LSM study was guided by the idea that a key point to improving the performance in terms of nickel release in the primary coolant would be to obtain a high chromium enrichment at the material surface, within a continuous and defect-free chromine layer, and without subsurface chromium depletion. There is a marked constrast about the $\mathrm{Cr} / \mathrm{Ni}$ dependence on the process parameters between the smoothness of Fig. 8 and the large amplitude variations of Fig. 9. These results point to a transition between different regimes anywhere between $70 \%$ and $80 \%$ overlap. At $50 \%$ overlap (Fig. 9), there is either no molten zone or a molten zone that remains thin and shortlived, even at the highest fluence used here $\left(6.7 \mathrm{~J} / \mathrm{cm}^{2}\right)$, so that the sample surface geometry is hardly perturbed. By contrast (Fig. 10) beyond $70 \%$ overlap the amplification coefficient A (as defined in Section 2.2) rises sharply, inducing an extended excursion into the molten state which at $90 \%$ overlap results in strong surface perturbations, possibly including remixing of the oxide layer. Additionally, $90 \%$ overlap results in very inhomogeneous concentration profiles, with spherical metallic nickel precipitates and chromium depletion in a sublayer due to enhanced chromium diffusion. This implies that the quality and repeatability of the chromium enrichment can only be obtained for up to about $70 \%$ overlap, i.e. avoiding the passage through an extended molten pool.

The ratio $\tau / \mathrm{T}$ of the pulse period to the pulse duration is of the order of 350. Laser-induced evaporation occurs during the laser pulse when very high temperatures are reached locally at the very surface, while melt depth and width, transport of chemical species in the condensed phase rather depend on the average power and temperature. Since the melting temperatures of $\mathrm{TiC}$ and $\mathrm{TiN}$ are respectively $\mathrm{Tm}=3067^{\circ} \mathrm{C}$ and $\mathrm{Tm}=2950{ }^{\circ} \mathrm{C}[53]$ their disappearance strongly hints to the fact that the temperature went up beyond these thresholds for laser energy densities above $4.3 \mathrm{~J} / \mathrm{cm}^{2}$. Such values are indeed confirmed by preliminary modelling results [59].

The preferential vaporization of iron compared to that of chromium and nickel, as evidenced by the aerosol analysis for energy density smaller than $5 \mathrm{~J} / \mathrm{cm}^{2}$ and overlap smaller than $70 \%$, is consistent with the lack of iron on the first nanometers underneath the surface of the treated samples revealed by GDOES. By contrast, the fact that at $90 \%$ overlap and energy density higher than $5 \mathrm{~J} / \mathrm{cm}^{2}$ aerosol composition is identical to that of the bulk shows that a thick layer of material has been removed by the treatment, which is unnecessary.

Given that the equilibrium vapour pressure of $\mathrm{Cr}$ is between 2 and 3 times larger than that of $\mathrm{Ni}$ or $\mathrm{Fe}$ in the 2800 to $4000 \mathrm{~K} \mathrm{Cr}$ evaporation is clearly hindered in most cases, suggesting that its immobilization in the sample could be induced by its oxidation.

A mechanism contributing to incorporation of oxygen at depth is the relocation of the material involved in the fluid motion which occurs during the laser pulse. This fluid motion, which was evidenced by surface morphology as discussed in Section 3.1 (Fig. 3), may be due to either the recoil pressure linked to evaporation or to Marangoni stress. The overlap ratio obviously has a strong influence on the mixing associated with this relocation of material. This mechanism is apparently favourable to the formation of the protective chromine layer.

No experimental work in this study was specifically dedicated to investigating the mechanisms of chromium enrichment and oxidation. We just observe that our results are consistent with other studies which have put forward some major aspects influencing surface chemistry during LSM treatment. Very fast heating/cooling results in smaller grain size and the high amount of grain boundaries enhances $\mathrm{Cr}$ diffusion [35]. It also promotes planar solidification. Segregation of chromium at the surface has long been known to occur during surface treatment of metallic alloys using nanosecond-pulsed lasers $[60,61]$. The strong affinity of $\mathrm{Cr}$ for oxygen contributes to selective oxidation of $\mathrm{Cr}$ at the surface. The combination of all these mechanisms is commonly invoked to explain Cr enrichment within the first $10 \mathrm{~nm}$ of the surface [62].

In summary, the laser-aided chromium enrichment, which in our experiments was shown to be favoured by low energy-densities and middle-range overlap, may result from a combination of factors including chromium rejection across the liquid/solid planar front during solidification, chromium migration towards the surface and its immobilization favored by a strong affinity with oxygen. 
With respect to our objective of preventing nickel release in the primary coolant medium, the LSM treatment carried out with a laser energy density of $3.6 \mathrm{~J} / \mathrm{cm}^{2}$ and $70 \%$ overlap appeared as the most promising as it results in a surface layer which is continuous, enriched in $\mathrm{Cr}_{2} \mathrm{O}_{3}$ and maximally depleted in nickel at the surface. This laser treatment was therefore selected and applied to samples submitted to the corrosion test in the primary coolant medium as described in Section 3.4 using the PETER facility $[2,49]$. The total amount of nickel released during the several stages is shown in Fig. 12. In order to make the units more meaningful, we note that the total amount of nickel released in the case of the raw surface $\left(12.6 \mu \mathrm{g} / \mathrm{dm}^{2}\right)$ is equal to the amount of nickel contained in a $0.5 \mathrm{~nm}$ thick layer of the bulk solid alloy (taking into account its nominal 30 at $\% \mathrm{Ni}$ content). It also corresponds to atoms either making up just a few atomic layers at the sample surface or having diffused through a small number of atomic layers, say between 2 and 5 approximately. Chromium concentration in the fluid remained below the detection limit (i.e. $200 \mathrm{ppt}$ ). Iron and other minor components of the alloy such as $\mathrm{Cu}, \mathrm{Mn}$ and Ti appeared in the fluid during the heating stage with measurable but very low concentrations in the ppb range.

The LSM treatment strongly influences the nickel release rate in the heating phase, reducing by a factor 7 the total amount of Ni released. Its influence is also strong and favourable in the final cooling phase, with a factor 3 over the raw sample.

This heating phase is the one during which, based on previous experience in this test loop, the amount of nickel released was expected to be the largest while a protective layer builds up and stabilizes.

By contrast, during the main stage there is hardly any difference between both samples. The time evolution of the nickel release rate during the main stage in shown in Fig. 13. The release rate steadily decreases for about the first $220 \mathrm{~h}$ where it becomes too small to be measurable. Then it remains close to zero for the following $380 \mathrm{~h}$. Overall both raw and LSM treated samples behave similarly during the main stage except that the initial release rate of the raw sample is about 3 times higher that for the LSM treated sample, consistently with the heating phase. This behaviour is consistent with the fact that oxide films formed in nominal primary chemistry are always protective [11].

During the cooling phase nickel release occurs again, with a rate of the same order of magnitude as during the heating phase, and again at a much higher rate for the raw sample than for the LSM treated sample. Previous work has shown that during this cooling phase the amount of nickel released depends on the passivation of the surface during exposure to the primary medium [2] and that a variety of behaviours may be

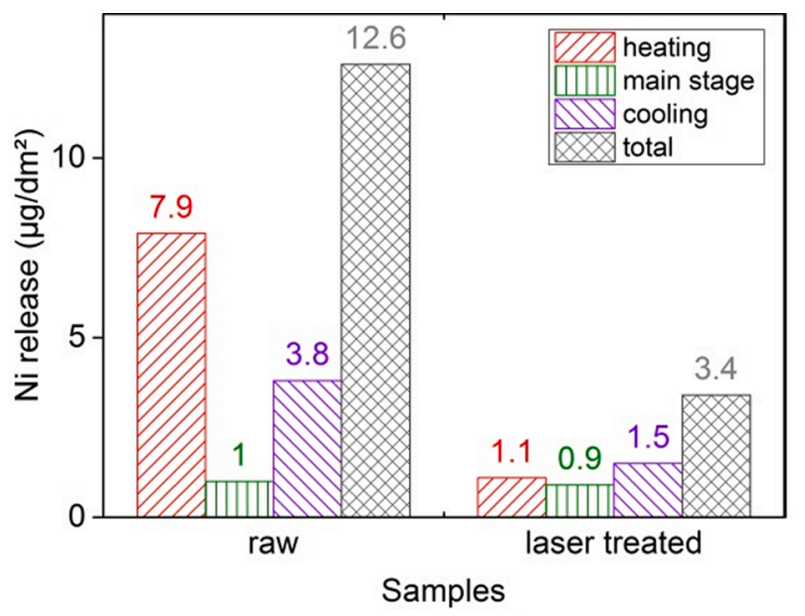

Fig. 12. Total nickel release during the three steps, as measured according to the protocol described in Section 2.4 and after integration over the respective step duration.

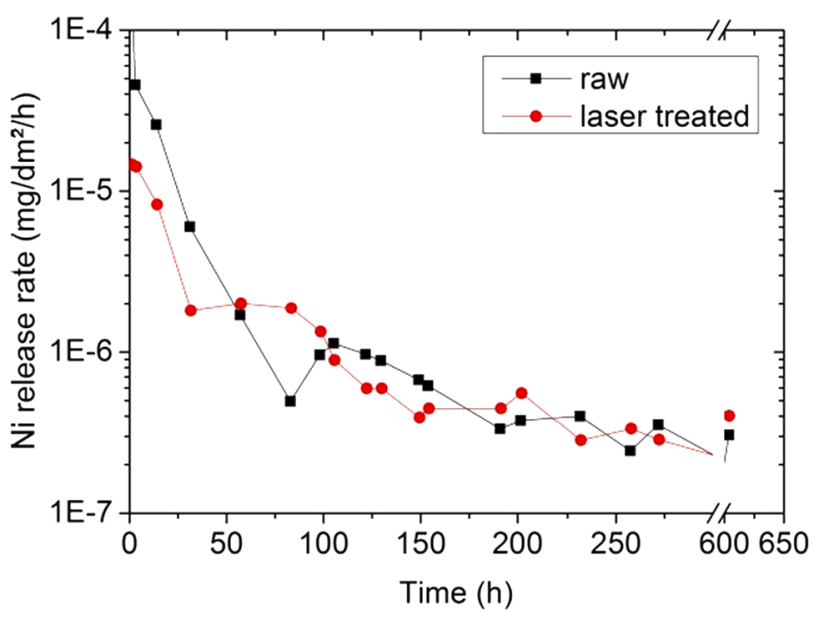

Fig. 13. Nickel release during the main stage as a function of time, as measured according to the protocol described in Section 2.4.

expected, depending on the material and possible surface modifications induced during the main stage.

Eventually the total amount of nickel released during the whole onemonth experiment was reduced by a factor of 3.7 by the LSM treatment.

The complete absence of chromium in the measured composition of the primary coolant shows that the chromium oxide layer was not dissolved during the test, as expected [8].

After the experiment in PETER the samples were observed by SEM. No morphological change on the surface could be detected at $20 \mu \mathrm{m}$ and $500 \mathrm{~nm}$ scale. The laser spots were still visible and no additional oxide grew during the test. Fig. 14 shows the GDOES spectra of the raw surface and the laser treated surface, recorded after exposure in nominal primary coolant. Both kinds of samples show globally similar concentration profiles, including an identical thickness of the modified layer of about $40 \mathrm{~nm}$. As for the XPS results (Table 5), they agree with GDOES and also contribute to show that both kinds of samples come out of the loop test with more or less the same surface composition and profiles. The XPS analysis on the first ten nanometers were carried out before and after the test in the loop. After the test the detected metallic elements are all in an oxidized state. The molar fractions of metallic elements in Table 5 are such that $\% \mathrm{Cr}+\% \mathrm{Fe}+\% \mathrm{Ni}+\% \mathrm{Ti}=100 \%$. There is a slight difference between Table 5 and Table 4 for the data relative to the raw samples before the Ni release experiment. We attribute this difference to the fact that for Table 5 the samples were electropolished.

The evolution of the raw sample during the loop test, as displayed by GDOES data of Fig. 7a and Fig. 14a, is quite significant. The amount of metal atoms that have been released into the solution is a completely negligible contribution to this evolution since, as discussed above, it is equivalent to a bulk material layer of about $0.0005 \mu \mathrm{m}$. Thus the evolution consists of two main trends: oxygen intake coming from the liquid and reorganization of the chemical elements, mostly $\mathrm{Ni}$ vs. $\mathrm{Cr}$, in the surface layer, due to chemically assisted diffusion occurring simultaneously with the growth of an oxide layer. A possible interpretation of the final concentration profile is that chromium diffusion is slowed down by oxidation while nickel diffusion through the oxide layer remains efficient.

The same mechanisms are active in the LSM treated sample during the loop test but the GDOES profile before the loop test (Fig. 7b) already includes a subsurface $\mathrm{Ni}$ depletion and a $\mathrm{Cr}$-enriched oxide layer. The evolution during the loop test consists mainly in a softening of the concentration gradients, especially that of $\mathrm{Ni}$ which decreases from a very high LSM induced value of $5 \% / \mathrm{nm}$ down to $1.7 \% / \mathrm{nm}$ after the loop test. Indeed the LSM affected thickness is about $8 \mathrm{~nm}$, as sketched on Fig. $14 \mathrm{~b}$ as a guide for the eye. (Note that its precise position along the horizontal axis is not known). We also note a conspicuous change of sign 
a)

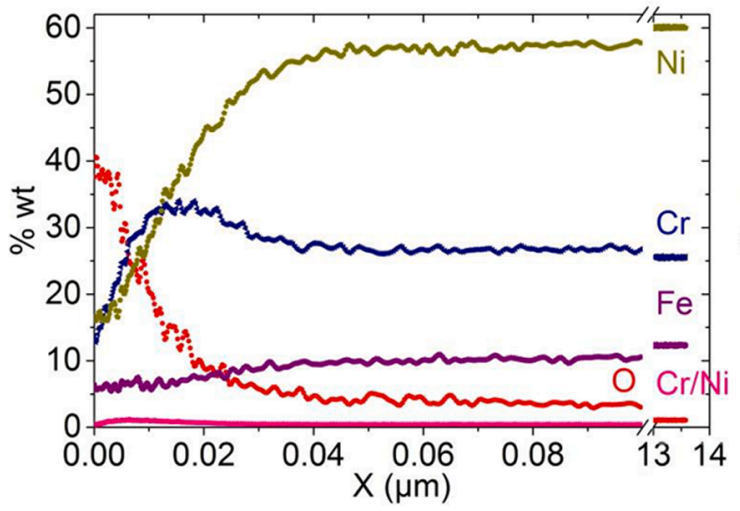

b)

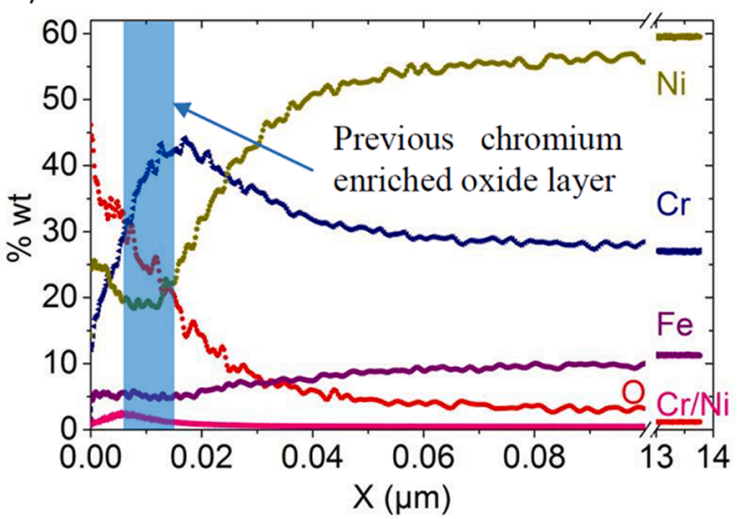

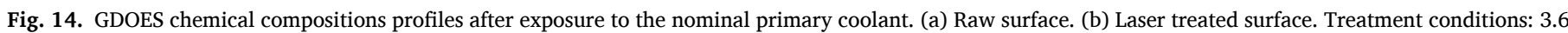
$\mathrm{J} / \mathrm{cm}^{2}$ and $70 \%$ overlap.

Table 5

Surface composition in oxidized species measured using XPS before and after exposure to the nominal primary coolant. The contributions are normalized so that $\% \mathrm{Cr}+\% \mathrm{Fe}+\% \mathrm{Ni}+\% \mathrm{Ti}=100 \%$.

\begin{tabular}{lllllll}
\hline & & $\mathrm{Cr}$ & $\mathrm{Fe}$ & $\mathrm{Ni}$ & $\mathrm{Ti}$ & $\mathrm{Cr} / \mathrm{Ni}$ \\
\hline \multirow{2}{*}{ Raw surface } & Before & 59 & - & 41 & - & 1.5 \\
\multirow{3}{*}{ Laser-treated surface } & After & 17 & 4 & 68 & 11 & 0.25 \\
& Before & 86 & 3 & - & 11 & $\gg$ \\
& After & 15 & 6 & 75 & 6 & 0.2 \\
\hline
\end{tabular}

of the Ni concentration gradient in the first $10 \mathrm{~nm}$ of the surface for which we have no explanation at this point.

If the GDOES profiles of Fig. 14 can be considered representative of the state of the samples at the end of the main stage of the loop test, their similarity is consistent with the similarity of the release rates of Fig. 13.

The Ni concentration at the extreme surface $\mathrm{x}_{\mathrm{Ni}}(0)$ does not correlate directly with the nickel release rate itself. For example for the LSM treated sample the release rate in the heating phase is significant while $\mathrm{x}_{\mathrm{Ni}}(0)=0$, whereas the release rate goes down to zero during the main stage while $\mathrm{x}_{\mathrm{Ni}}(0) \approx 20 \%$. Another example is provided by the cooling phase where the raw sample releases 3 times more than the LSM treated sample while the surface compositions are similar. Thus other factors are involved in the release rate, which could be the microstructure, grain size, composition of the grain boundaries and speciation or chemical potentials of the elements.

Thus, while the beneficial influence of the LSM treatment is very clearly revealed in the loop test itself, an interpretation of this global result by a description in terms of microscopic mechanisms is still elusive.

It has been shown that the kinetics of cation release strongly depend on the density of structural defects located in the alloy subsurface region in specimens whose microstructure was perturbed by cold-work prior to the corrosion tests [20]. Thus a possible contribution to the reduction in the Ni release rate after the LSM treatment could be a reduction of the defect density in the microstructure.

On the laser treated surface the exposure to nominal primary coolant increased the oxide layer thickness from $8 \mathrm{~nm}$ to $20 \mathrm{~nm}$ but the oxygen content at the surface decreased from $60 \%$ to $40 \%$. The chromium enriched oxide layer before the exposure into the primary loop is indicated in blue in Fig. 14. The chemical composition of the oxide layer was also changed. The content of $\mathrm{Ni}$ underneath the surface rose, indicating the diffusion of $\mathrm{Ni}$ towards the previous chromium enriched oxide layer.

XPS analyses revealed that the metallic elements are oxidized as $\mathrm{Ni}^{2+}, \mathrm{Cr}^{3+}$ and $\mathrm{Fe}^{3+}$. pointing to the formation of $(\mathrm{Ni}, \mathrm{Fe})$ spinels and $(\mathrm{Ni}$, $\mathrm{Cr}$ ) spinels on both surfaces (raw and LSM treated surfaces). The only difference was the emergence of $\mathrm{Ni}(\mathrm{OH})_{2}$ on the raw surface and $\mathrm{NiO}$ on the laser treated surface, a fact which could be crucial in the interpretation of the difference in nickel release rates. This finding is not explained yet and deserves further investigation.

Precipitation of $\mathrm{Ni}(\mathrm{OH})_{2}$ in the primary medium can explain the higher nickel released amount. However, on the laser treated surface, enriched in chromium oxide, $\mathrm{NiO}$ reacted with the $\mathrm{Cr}_{2} \mathrm{O}_{3}$ giving $\mathrm{NiCr}_{2} \mathrm{O}_{4}$ which healed the material from releasing more nickel in the medium.

Similar findings were obtained by Moeglen [15]. Oxide growth mechanism for nickel alloys in hydrogen containing pressurized water has been modelled by numerous authors $[3,6,12]$ but those results are still insufficient to explain the impact of the oxide composition and structure on the speciation of nickel at the surface and particularly the selective formation of nickel hydroxide or nickel oxides. These observations would deserve further investigations.

\section{Conclusions}

Laser surface melting (LSM) treatment of alloy 690 was performed using a sub-microsecond pulsed laser. A set of operating parameters was identified that leads to a surface layer made of chromium oxide about 8 $\mathrm{nm}$ thick with a satisfactory surface state, no more than a few percents of nickel within the first $\mathrm{nm}$ and without any chromium depletion in the substrate. This treatment led to an overall reduction by a factor 3.7 of the total amount of Ni released in the standard $650 \mathrm{~h}$ test performed in the PETER loop simulating operating conditions of a nuclear reactor. During the heating phase, nickel release was reduced by a factor of 7 . The time-resolved data allow us to predict that a 10 times longer exposure to the primary coolant at $325^{\circ} \mathrm{C}$ and $15.5 \mathrm{MPa}$ would lead to no measurable increase in the amount of nickel released. This is a very significant improvement over conventional surface treatments which illustrates the uniqueness of the laser as a means for bringing about a major change at the very surface without perturbing the bulk. An oxide layer is present with or without the LSM treatment but the protection it offers against nickel release is drastically improved by the LSM treatment.

Nickel release of the LSM treated surface in the coolant loop occurs almost exclusively during the heating and cooling phases. Thus in a pragmatic approach to the industrial problem the LSM treatment such as described here, by reducing the release rate during these critical phases by an order of magnitude, is a satisfactory solution.

Further work will address the relationship between the microstructure of the oxide layer and the residual Ni release rate during the transient heating and cooling phases. There remains several LSM treatment parameters which have not yet been investigated and could be tuned to improve on this behaviour. 


\section{CRediT authorship contribution statement}

Wilfried Pacquentin: Data curation, Formal analysis, Investigation, Methodology, Supervision. Lucille Gouton: Data curation, Formal analysis, Investigation. Nadège Caron: Conceptualization, Formal analysis, Methodology, Project administration, Resources, Supervision. Charles Brussieux: Investigation, Resources. Marc Foucault: Conceptualization, Funding acquisition, Resources. Patrice Peyre: Methodology. Hicham Maskrot: . Véronique Favier: Methodology, Supervision.

\section{Declaration of Competing Interest}

The authors declare that they have no known competing financial interests or personal relationships that could have appeared to influence the work reported in this paper.

\section{Acknowledgment}

The authors acknowledge Cécile Blanc, Jérôme Varlet for the SEM analysis, Michel Tabarant for GDOES and ICP-OES, Frédéric Miserque for XPS tests and Philippe Zeller for fruitful discussions.

\section{References}

[1] M. Bioulac, M.F. Cipiere, G. Poudroux, F. Champigny, L. Mercier, Y. Rouillon, F. Vaillant, Replacement of alloy 600 by alloy 690 for steam generator tubes and closure heads in PWR, in: Rep. INIS-FR-4141, INIS, Paris, France, 2004: pp. 179-188. http://inis.iaea.org/Search/search.aspx?orig_q=RN:37040643.

[2] N. Engler, C. Brun, M. Guillodo, Optimization of SG Tubes Prefilming Process to Reduce Nickel Release, in: NPC 08 Int. Conf. Water Chem. Nucl. React. Syst., VGB Powertech, Berlin, Germany, 2008: pp. 251-256. https://www.vgb.org/shop/ buecher/tagungsbande/tb430-08-cd.html.

[3] F. Carrette, M.C. Lafont, G. Chatainier, L. Guinard, B. Pieraggi, Analysis and TEM examination of corrosion scales grown on Alloy 690 exposed to pressurized water at $325{ }^{\circ} \mathrm{C}$, Surf. Interf. Anal. 34 (1) (2002) 135-138, https://doi.org/10.1002/ sia. 1269.

[4] G.J. Abraham, R. Bhambroo, V. Kain, R. Shekhar, G.K. Dey, V.S. Raja, Electrochemical characterization of oxide film formed at high temperature on Alloy 690, Nucl. Eng. Des. 243 (2012) 69-75, https://doi.org/10.1016/j. nucengdes.2011.11.018.

[5] P.M. Scott, P. Combrade, General corrosion and stress corrosion cracking of Alloy 600 in light water reactor primary coolants, J. Nucl. Mater. 524 (2019) 340-375, https://doi.org/10.1016/j.jnucmat.2019.04.023.

[6] L. Marchetti, S. Perrin, F. Jambon, M. Pijolat, Corrosion of nickel-base alloys in primary medium of pressurized water reactors: New insights on the oxide growth mechanisms and kinetic modelling, Corros. Sci. 102 (2016) 24-35, https://doi.org/ 10.1016/j.corsci.2015.09.001.

[7] C. Marks, M. Little, P. Krull, Dennis Hussey, Kenny Epperson, Evaluating Steam Generator Tubing Corrosion through Shutdown Nickel and Cobalt Releases, in: NPC 2012 Nucl. Plant Chem. Conf. Int. Conf. Water Chem. Nucl. React. Syst., INIS, Paris (France), 2012: p. 28. https://inis.iaea.org/Search/searchsinglerecord.aspx? recordsFor $=$ SingleRecord $\& \mathrm{RN}=46071788$.

[8] L. Guinard, C. Gabet, T. Czerwiec, E. Riquelme, O. Kerrec, Effect of surface passivation of Inconel 690 on oxidation in primary circuit conditions, EDF, Les Renardières, France, 2000.

[9] P. Combrade, P.M. Scott, M. Foucault, E. Andrieu, P. Marcus, Oxidation of Ni base alloys in PWR water: oxide layers and associated damage to the base metal, in: Proc. 12th Int. Conf. Environ. Degrad. Mater. Nucl. Power Syst. - Water React. TMS - Minerals Metals and Materials Society, Salt Lake City, Utah, 2005: pp. 883-890. http://www.proceedings.com/00334.html.

[10] T. Baldridge, G. Poling, E. Foroozmehr, R. Kovacevic, T. Metz, V. Kadekar, M. C. Gupta, Laser cladding of Inconel 690 on Inconel 600 superalloy for corrosion protection in nuclear applications, Opt. Lasers Eng. 51 (2) (2013) 180-184, https://doi.org/10.1016/j.optlaseng.2012.08.006.

[11] M. Clauzel, M. Guillodo, M. Foucault, N. Engler, F. Chahma, C. Brun, Correlation between Ni base alloys surface conditioning and cation release mitigation in primary coolant, in: NPC 2010 Conf. Proc, Canadian Nuclear Society, Canada, 2010, p. 12.

[12] J. Chen, Z. Lu, F. Meng, X. Xu, Q. Xiao, H.-S. Kim, C. Jang, The corrosion behaviour of alloy 690 tube in simulated PWR secondary water with the effect of solid diffusing hydrogen, J. Nucl. Mater. 517 (2019) 179-191, https://doi.org/10.1016/ j.jnucmat.2019.02.019.

[13] K.M. Kim, H.-S. Shim, M.J. Seo, D.H. Hur, Corrosion Control of Alloy 690 by Shot Peening and Electropolishing under Simulated Primary Water Condition of PWRs, Adv. Mater. Sci. Eng. (2015) 1-9, https://doi.org/10.1155/2015/357624.

[14] C. Rives, T. Czerwiec, T. Belmonte, O. Kerrec, H. Michel, Surface passivation of Inconel 690 in flowing Ar-O2-H2 microwave post-discharges, in: Proc. ICONE 8 8th Int. Conf. Nucl. Eng., ASME, Baltimore, MD USA, 2000: p. ICONE-8287.
[15] M. Moeglen, Modification of the surface reactivity of a nickel based alloy in order to limit the release of nickel in primary media of pressurized water reactors, Université de Grenoble Alpes, 2015. http://inis.iaea.org/search/search.aspx?orig $\mathrm{q}=\mathrm{RN}: 47093507$.

[16] A. Seyeux, V. Maurice, P. Marcus, Oxide Film Growth Kinetics on Metals and Alloys: I. Physical Model, J. Electrochem. Soc. 160 (6) (2013) C189-C196, https:// doi.org/10.1149/2.036306jes.

[17] H. Lefaix-Jeuland, L. Marchetti, S. Perrin, M. Pijolat, M. Sennour, R. Molins, Oxidation kinetics and mechanisms of Ni-base alloys in pressurised water reactor primary conditions: Influence of subsurface defects, Corros. Sci. 53 (12) (2011) 3914-3922, https://doi.org/10.1016/j.corsci.2011.07.024.

[18] Y.S. Lim, D.J. Kim, S.W. Kim, S.S. Hwang, H.P. Kim, Characterization of internal and intergranular oxidation in Alloy 690 exposed to simulated PWR primary water and its implications with regard to stress corrosion cracking, Mater. Charact. 157 (2019) 109922, https://doi.org/10.1016/j.matchar.2019.109922.

[19] J. Panter, B. Viguier, J.-M. Cloué, M. Foucault, P. Combrade, E. Andrieu, Influence of oxide films on primary water stress corrosion cracking initiation of alloy 600 , J. Nucl. Mater. 348 (1-2) (2006) 213-221, https://doi.org/10.1016/j. jnucmat.2005.10.002.

[20] F. Carrette, L. Guinard, B. Pieraggi, Kinetics of corrosion products release from nickel-base alloys corroding in primary water conditions. A new modeling of release, in: Proc. Int. Conf. Water Chem. React. Syst., Avignon, France, 2002. http://inis.iaea.org/Search/search.aspx?orig_q=RN:34065466 (accessed April 5, 2021).

[21] J. Yang, Y. Li, A. Xu, B. Fekete, D.D. Macdonald, The electrochemical properties of alloy 690 in simulated pressurized water reactor primary water: Effect of temperature, J. Nucl. Mater. 518 (2019) 305-315, https://doi.org/10.1016/j. jnucmat.2019.03.016.

[22] Y. Hemmi, N. Ichikawa, N. Saito, T. Masuda, Electrochemical Considerations Regarding General Corrosion of Materials in a BWR Primary Circuit, J. Nucl. Sci. Technol. 31 (11) (1994) 1202-1213, https://doi.org/10.1080/ 18811248.1994.9735277.

[23] A.C.S. Sabioni, A.M. Huntz, J.N.V. Souza, M.D. Martins, F. Jomard, Diffusion of nickel in single- and polycrystalline Cr2O3, Philos. Mag. 88 (3) (2008) 391-405, https://doi.org/10.1080/14786430701848046.

[24] G.C. Allen, J.M. Dyke, S.J. Harris, A. Morris, The oxidation of Inconel-690 alloy at $600 \mathrm{~K}$ in air, Appl. Surf. Sci. 31 (2) (1988) 220-238, https://doi.org/10.1016/ 0169-4332(88)90063-3.

[25] J. Dutta Majumdar, I. Manna, Laser processing of materials, Sadhana 28 (3-4) (2003) 495-562, https://doi.org/10.1007/BF02706446.

[26] O.V. Akgün, M. Ürgen, A.F. Çakir, The effect of heat treatment on corrosion behavior of laser surface melted 304L stainless steel, Mater. Sci. Eng. A. 203 (1-2) (1995) 324-331, https://doi.org/10.1016/0921-5093(95)09807-0.

[27] P.K. Samantaroy, S. Girija, R. Kaul, U. Kamachi Mudali, Enhancement of corrosion resistance of nickel based superalloys by laser surface melting, Surf. Eng. 29 (7) (2013) 522-530, https://doi.org/10.1179/1743294413Y.0000000147.

[28] F.H. Stott, P.K.N. Bartlett, G.C. Wood, The influence of laser surface treatment on the high temperature oxidation of $\mathrm{Cr} 2 \mathrm{O} 3$-forming alloys, Mater. Sci. Eng. 88 (1987) 163-169, https://doi.org/10.1016/0025-5416(87)90081-4.

[29] A. Conde, I. García, J.J. de Damborenea, Pitting corrosion of 304 stainless steel after laser surface melting in argon and nitrogen atmospheres, Corros. Sci. 43 (5) (2001) 817-828, https://doi.org/10.1016/S0010-938X(00)00114-1.

[30] C.Y. Cui, Y.X. Shu, X.G. Cui, J.D. Hu, Microstructure evolution and wear behavior of AISI 304 stainless steel after Nd:YAG pulsed laser surface melting, Appl. Opt. 59 (2020) 10862-10869, https://doi.org/10.1364/AO.406214.

[31] W. Pacquentin, C. Blanc, N. Caron, P.-Y. Thro, A. Chénière, M. Tabarant, G. Moutiers, F. Miserque, H. Plouzennec, R. Oltra, Renforcement de la résistance à la corrosion localisée de l'acier inoxydable 304L grâce au traitement de surface par laser impulsionnel, Rev. Métallurgie. 110 (2) (2013) 175-183, https://doi.org/ $10.1051 / \mathrm{metal} / 2013061$.

[32] U. Kamachi Mudali, R.K. Dayal, G.L. Goswami, Laser surface melting for improving intergranular corrosion resistance of cold-worked and sensitised type 316 stainless steel, Anti-Corros. Methods Mater. 45 (3) (1998) 181-188, https://doi.org/ 10.1108/00035599810216902.

[33] N. Ahmed, M.S. Bakare, D.G. McCartney, K.T. Voisey, The effects of microstructural features on the performance gap in corrosion resistance between bulk and HVOF sprayed Inconel 625, Surf. Coat. Technol. 204 (14) (2010) 2294-2301, https://doi.org/10.1016/j.surfcoat.2009.12.028.

[34] P.S.N. Stokes, F.H. Stott, G.C. Wood, The influence of laser surface treatment on the high-temperature oxidation of Cr2O3-forming alloys, Mater. Sci. Eng. A. 120-121 (1989) 549-554, https://doi.org/10.1016/0921-5093(89)90814-9.

[35] W. Pacquentin, N. Caron, R. Oltra, Nanosecond laser surface modification of AISI 304L stainless steel: Influence the beam overlap on pitting corrosion resistance, Appl. Surf. Sci. 288 (2014) 34-39, https://doi.org/10.1016/j.apsusc.2013.09.086.

[36] J. Stasic, B. Gakovic, A. Krmpot, V. Pavlovic, M. Trtica, B. Jelenkovic, Nickel-based super-alloy Inconel 600 morphological modifications by high repetition rate femtosecond Ti:sapphire laser, Laser Part. Beams. 27 (4) (2009) 699-707, https:// doi.org/10.1017/S0263034609990425.

[37] G. Bao, K. Shinozaki, M. Inkyo, T. Miyoshi, M. Yamamoto, Y. Mahara, $\mathrm{H}$. Watanabe, Modeling of precipitation and Cr depletion profiles of Inconel 600 during heat treatments and LSM procedure, J. Alloys Compd. 419 (1-2) (2006) 118-125, https://doi.org/10.1016/j.jallcom.2005.10.009.

[38] G. Bao, M. Yamamoto, K. Shinozaki, Precipitation and $\mathrm{Cr}$ depletion profiles of Inconel 182 during heat treatments and laser surface melting, J. Mater. Process. Technol. 209 (1) (2009) 416-425, https://doi.org/10.1016/j. jmatprotec.2008.02.021. 
[39] Z. Liu, H. Liu, F. Viejo, Z. Aburas, M. Rakhes, Laser-induced microstructural modification for corrosion protection, Proc. Inst. Mech. Eng. Part C J. Mech. Eng. Sci. 224 (5) (2010) 1073-1085, https://doi.org/10.1243/09544062JMES1858.

[40] T. Emi, W.M. Boorstein, R.D. Pehlke, Absorption of gaseous oxygen by liquid iron, Metall. Trans. 5 (9) (1974) 1959-1966, https://doi.org/10.1007/BF02644486.

[41] C. Cui, J. Hu, Y. Liu, Z. Guo, Microstructure evolution on the surface of stainless steel by Nd:YAG pulsed laser irradiation, Appl. Surf. Sci. 254 (11) (2008) 3442-3448, https://doi.org/10.1016/j.apsusc.2007.11.035.

[42] S.I. Anisimov, V.A. Khokhlov, Instabilities in laser-matter interaction, CRC Press, Boca Raton, FL, 1995.

[43] R.S. Dutta, R. Tewari, P.K. De, Effects of heat-treatment on the extent of chromium depletion and caustic corrosion resistance of Alloy 690, Corros. Sci. 49 (2) (2007) 303-318, https://doi.org/10.1016/j.corsci.2006.05.043.

[44] C. Liu, X. Mao, S.S. Mao, R. Greif, R.E. Russo, Particle Size Dependent Chemistry from Laser Ablation of Brass, Anal. Chem. 77 (20) (2005) 6687-6691, https://doi. org/10.1021/ac0508696.

[45] V. Bulatov, A. Khalmanov, I. Schechter, Study of the morphology of a laserproduced aerosol plume by cavity ringdown laser absorption spectroscopy, Anal. Bioanal. Chem. 375 (8) (2003) 1282-1286, https://doi.org/10.1007/s00216-0031775-7.

[46] Y. Chen, V. Bulatov, L. Singer, J. Stricker, I. Schechter, Mapping and elemental fractionation of aerosols generated by laser-induced breakdown ablation, Anal. Bioanal. Chem. 383 (7-8) (2005) 1090-1097, https://doi.org/10.1007/s00216005-0126-2.

[47] Y.S. Lim, J.S. Kim, H.S. Kwon, Effects of sensitization treatment on the evolution of Cr carbides in rapidly solidified Ni-base Alloy 600 by a CO2 laser beam, Mater. Sci. Eng. A. 279 (1-2) (2000) 192-200, https://doi.org/10.1016/S0921-5093(99) 00615-2.

[48] Y.S. Lim, J.S. Kim, H.S. Kwon, Particle formation in the rapidly solidified zone of alloy 600 surface melted by a CO2 laser beam, Metall. Mater. Trans. A. 32 (5) (2001) 1248-1251, https://doi.org/10.1007/s11661-001-0134-6.

[49] I. Ganzmann, D. Hille, U. Staude, PETER loop. Multifunctional test facility for thermal hydraulic investigations of PWR fuel elements, in: Annu. Meet. Nucl. Technol. 2009, Dresden (Germany), 2009. http://inis.iaea.org/Search/search. aspx?orig_q=RN:42029477 (accessed May 15, 2020).

[50] A.-F. Soveja, Modélisation du processus de texturation par faisceau laser : approches expérimentale et numérique, Université de Bourgogne, 2007.

[51] R. Escobar Galindo, R. Gago, J.M. Albella, R. Escobar Galindo, R. Gago, A. Lousa, Comparative depth-profiling analysis of nanometer-metal multilayers by ion- probing techniques, TrAC Trends Anal. Chem. 28 (4) (2009) 494-505, https://doi. org/10.1016/j.trac.2009.01.004.

[52] W. Pacquentin, N. Caron, R. Oltra, Effect of microstructure and chemical composition on localized corrosion resistance of a AISI 304L stainless steel after nanopulsed-laser surface melting, Appl. Surf. Sci. 356 (2015) 561-573, https://doi. org/10.1016/j.apsusc.2015.08.015.

[53] J.E. Greene, J.-E. Sundgren, L. Hultman, I. Petrov, D.B. Bergstrom, Development of preferred orientation in polycrystalline TiN layers grown by ultrahigh vacuum reactive magnetron sputtering, Appl. Phys. Lett. 67 (20) (1995) 2928-2930, https://doi.org/10.1063/1.114845.

[54] S. Mokadem, Epitaxial laser treatment of single crystal nickel-base superalloys, EPFL (2004), https://doi.org/10.5075/epfl-thesis-3127.

[55] D.R. Gaskell, Introduction to the Thermodynamics of Materials, Fifth ed., Taylor \& Francis, New York - London, 2012.

[56] Special Metals Corporation, Properties of INCONEL alloy 690, Special Metals Corporation, USA, 2009. https://www.specialmetals.com/assets/smc/documen ts/alloys/inconel/inconel-alloy-690.pdf.

[57] J.R. Davis, ed., Nickel, Cobalt, and Their Alloys, ASM International, ASM International, Materials Park, OH, 2000. https://www.asminternational.org/ documents/10192/1849770/ACFA9DA.pdf.

[58] K.-H. Leitz, B. Redlingshöfer, Y. Reg, A. Otto, M. Schmidt, Metal Ablation with Short and Ultrashort Laser Pulses, Phys. Procedia. 12 (2011) 230-238, https://doi. org/10.1016/j.phpro.2011.03.128.

[59] L. Gouton, M. Dal, P. Aubry, H. Maskrot, N. Caron, W. Pacquentin, M. Foucault, P. Peyre, V. Favier, in: Oxide-layer formation on a nickel based alloy using laser surface melting - Experimental and numerical study of the laser-metal interaction, Laser Institute of America, Atlanta, Georgia, USA, 2015, pp. 536-543, 10.2351/ 1.5063201

[60] P.T. Cottrell, R.P. Frankenthal, G.W. Kammlott, D.J. Siconolfi, C.W. Draper, Effect of Laser Surface Melting on Some Corrosion Characteristics of an Iron-Chromium Alloy, J. Electrochem. Soc. 130 (5) (1983) 998-1001, https://doi.org/10.1149/ 1.2119930 .

[61] L. Marchetti-Sillans, Corrosion généralisée des alliages à base nickel en milieu aqueux à haute température : Apport à la compréhension des mécanismes, phdthesis, Ecole Nationale Supérieure des Mines de Saint-Etienne, 2007. https:// tel.archives-ouvertes.fr/tel-00991918.

[62] T.R. Jervis, D.J. Frydrych, D.R. Baer, Effect of excimer laser melting on the near surface chemistry and corrosion properties of aisi 304 stainless steel, Mater. Lett. 6 (7) (1988) 225-228, https://doi.org/10.1016/0167-577X(88)90026-2. 